\title{
High Temperature Shock Tube Experiments and Kinetic Modeling Study of Diisopropyl Ketone Ignition and Pyrolysis
}

\author{
Ghazal Barari $^{\mathrm{a}}$, Owen Pryor ${ }^{\mathrm{b}}$, Batikan Koroglu ${ }^{\mathrm{b}, \$}$, S. Mani Sarathyc, Artëm E. Masunov ${ }^{\mathrm{d}, \mathrm{e}}$, \\ Subith S. Vasu ${ }^{\text {b,\# }}$ \\ ${ }^{a}$ Aerospace and Mechanical Engineering Department, Embry-Riddle Aeronautical University, Prescott, AZ 86301, \\ USA \\ ${ }^{b}$ Mechanical and Aerospace Engineering, Center for Advanced Turbomachinery and Energy Research, University of \\ Central Florida, Orlando, FL 32816, USA \\ ${ }^{c}$ King Abdullah University of Science and Technology, Clean Combustion Research Center, Thuwal, 23955-6900, \\ Saudi Arabia \\ ${ }^{d}$ NanoScience Technology Center, Department of Chemistry, Department of Physics, and Florida Solar Energy \\ Center, University of Central Florida, Orlando, FL 32816, USA \\ ${ }^{e}$ National Research Nuclear University MEPhI, Kashirskoye shosse 31, Moscow, 115409, Russia \\ ${ }^{\$}$ Presently at Lawrence Livermore Lab, Livermore, CA \\ ${ }^{\#}$ Corresponding Author: subith@ucf.edu
}

\begin{abstract}
Diisopropyl ketone (DIPK) is a promising biofuel candidate, which is produced using endophytic fungal conversion. In this work, a high temperature detailed combustion kinetic model for DIPK was developed using the reaction class approach. DIPK ignition and pyrolysis experiments were performed using UCF shock tube. The shock tube oxidation experiments were conducted between $1093 \mathrm{~K}$ and $1630 \mathrm{~K}$ for different reactant compositions, equivalence ratios $(\varphi=0.5-2.0)$, and pressures $(1-6 \mathrm{~atm})$. In addition, methane concentration time-histories were measured during 2\% DIPK pyrolysis in argon using cw laser absorption near $3400 \mathrm{~nm}$ at temperatures between 1300 and $1400 \mathrm{~K}$ near $1 \mathrm{~atm}$. To the best of our knowledge, current ignition delay times (above $1050 \mathrm{~K}$ ) and methane time histories are the first such experiments performed in DIPK at high temperatures. Present data were used as validation targets for the new kinetic model and simulation results showed fair agreement compared to the experiments. The reaction rates corresponding to the main consumption pathways of DIPK were found to have high sensitivity in controlling the reactivity, so these were adjusted to attain better agreement between the simulation and experimental data. A correlation was developed based on the experimental data to predict the ignition delay times using the temperature, pressure, fuel concentration and oxygen concentration.
\end{abstract}

Keywords: Ignition delay time; Kinetic mechanism; Shock tube; Biofuel Oxidation; Diisopropyl Ketone. 


\section{Introduction}

Use of biofuels, especially in automotive applications, is a growing trend due to their potential to reduce the greenhouse gas concentrations in atmosphere. Researchers have been exploring various methods - including endophytic fungal conversion of cellulose - to efficiently produce biofuels in order to decrease our dependence on fossil fuels. One example of a biofuel that is successfully blended with fossil fuels is ethanol, and as a result the focus of biofuel combustion research during last 3 decades mainly fell on ethanol blends. Experts have predicted that liquid biofuels will be a significant part of future energy portfolio[1] and recently, there have been many innovative methods to produce biofuels [2-5]. Even though, biofuels are a promising renewable alternative to conventional petroleum fuels that could lower greenhouse gas emissions[6], the products that are most efficiently produced from biomass may not have well-characterized combustion properties as they represent a wide range of chemical structures which have varying ignition, oxidation, and emission characteristics. Therefore, probing the fuel molecular effects on combustion is vital and critical kinetics knowledge is warranted for other oxygenated chemical classes, including ketones and aldehydes, which so far received rather scarce attention in the literature [79].

One of the most promising platforms for cellulosic biofuel generation is to harness the metabolic processes of endophytic fungi that directly convert lignocellulosic material into a variety of volatile organic compounds [10-13]. The biofuel co-development framework was initiated at Sandia National Labs [14-16], which is similar to the "Tailor-Made Fuels from Biomass" approach from Europe[17]. Here, the synthetic biologists[14, 18, 19] develop and engineer a new platform for drop-in fuel production from lignocellulosic biomass, using several endophytic fungi including Hypoxylon CI-4A, EC-38, CO27A, and Daldinia EC-12. Fungal pathways are moreover particularly suited for synthetic bioengineering due to their relatively minimal genomes. Hence this process has the potential advantage that expensive pretreatment and fuel refining stages can be optimized thereby allowing scalability and cost reduction-two major considerations for widespread biofuel utilization. Large concentrations of ketones[20] along with other volatile organic compounds (VOC's) were produced by Hypoxylon CO27-A grown over 
swtichgrass media. The combustion and emission properties of these novel fungal biofuels (large ketones) are poorly known, and fundamental measurements of representative molecules are needed in order to provide feedback on their desirability in advanced combustion engines (e.g., HCCI: homogeneous, charge, compression and ignition engines) and their impact on emissions.

Most combustion studies in the literature focused on simple ketones such as, acetone[21-28] (simplest ketone), 3-pentanone[26, 29-31], and propanone[32]. Interesting to the current task are shock tube ignition investigations by Serinyel et al.[31, 33] for 3-pentanone and 2-butanone. Also, Black et al. [27] completed an experimental and numerical work on the ignition delay times, laminar flame speeds as well as a kinetic model for acetone using shock tube and spherical bomb. Pichon et al. [23] and Davidson et al. [34] have studied the ignition delay times of acetone at relatively high temperatures 1300-1900K. Recently, Hanson and co-workers [29, 35, 36] investigated ignition, pyrolysis, and oxidation of these ketones using shock tube and laser diagnostics technique. The premixed flames of three different $\mathrm{C}_{3}{ }^{-}$ oxygenated hydrocarbons (acetone, $n$-propanol, and $i$-propanol) were investigated at low pressure[37].

Very recently, ignition delay times of 2-butanone and 3-buten-2-one were measured using a shock tube to probe the effect of double bond. It is clear that combustion kinetics interests in ketones were mainly limited to small molecules due to their application as tracer-LIF species $[24,38]$ and critical ignition and oxidation data for realistic biofuel candidates are needed.

Di-isopropyl ketone (DIPK), 2,4-dimethyl-3-pentanone $\left(\mathrm{C}_{7} \mathrm{H}_{14} \mathrm{O}\right)$, is a prototype for biofuels produced by endophytic fungi $[14,39]$. DIPK is a branched ketone which is a potential candidate as a biofuel to be used in advanced homogeneous charge compression ignition (HCCI) engines [40]. A detailed study of DIPK was performed recently using experimental and modeling methods by Allen et al. [14] The detailed modeling of combustion phenomena is based on a comprehensive kinetic mechanism which includes details of several reactions and rate constants. In this regard, the smaller ketones such as, acetone and 2-butanone have been investigated theoretically and experimentally in terms of pyrolysis, 
reaction rates, and ignition delay times at different ranges of temperature [27, 28, 30, 35] up to $2000 \mathrm{~K}$. However, due to a limited number of studies on larger ketones, their ignition characteristics and chemistry of oxidation are not well documented. For the larger straight-chained and branched ketones, there are some measurements at combustion temperatures for ketone $+\mathrm{OH}$ reactions using shock tube [41]. The detailed reaction mechanism developed by Allen et al. used an automated approach called reaction mechanism generator (RMG) for DIPK [14] and focused on temperatures below 1000K. The model was verified against various experiments; however, the ignition delay time measured by shock tube and rapid compression machine for the temperature range of 590-1023 K near 10 bar showed significant discrepancies comparing to predictions. The significant shift in the NTC suggests that more investigations should be performed to develop a model capable of predicting the combustion behavior of DIPK. This mechanism was slightly modified [39] to be able to predict Sandia's HCCI engine experimental data [40] for fuel reactivity, required bottom dead center temperature versus combustion timing. However, discrepancies were not completely resolved at high temperature. The "auto" option in RMG suggests that the user is not required to specify conversions at which the edge reaction fluxes are estimated. The user also does not need to decide whether to add a new species in the core reaction model. This option saves a lot of computational time and costs. However, it may result in missing of some important reactions.

The goal of this study is to investigate DIPK oxidation and pyrolysis characteristics at high temperature and to gain insights into branched ketones decomposition and oxidation pathways. A detailed high temperature kinetic reaction mechanism for DIPK was developed based on successful reaction classes approach adopted for other hydrocarbon fuels in the literature [42-44]. To validate DIPK kinetic mechanisms new high temperature experimental targets are needed. A shock tube is an ideal facility to measure the ignition delay time and species time histories due to the use of shockwaves being utilized to compress and heat the mixture on microsecond time scales compared to the hundreds of microsecond time scales of the experiments $[27,30,41,45,46]$. The ignition delay times were measured at 1093-1630 $\mathrm{K}$ in a shock tube for different reactant fractions, equivalence ratios $(\varphi=0.5-2.0)$, and pressures (1-6 atm). The ignition delay time, defined as the time it takes for a mixture to ignite under a certain pressure and 
temperature is an important fundamental and design parameter for engine development. In addition, methane concentration time-histories were determined using laser absorption near $3400 \mathrm{~nm}$ during $2 \%$ DIPK pyrolysis (in argon) for temperatures between 1300 and $1400 \mathrm{~K}$ near $1 \mathrm{~atm}$. The agreement between current simulations and experimental data validates the model to be employed to interpret the oxidation pathway of DIPK.

\section{Experimental Procedure}

\subsection{Shock Tube and Mixing Facility}

The high purity kinetics shock tube located at the University of Central Florida (UCF) was used for all experiments (for details refer [47]). The UCF shock tube is made of electro-polished stainless steel with an $\mathrm{ID}=14.17 \mathrm{~cm}$ and utilized lexan diaphragms (thickness $5-20 \mathrm{~mm}$ ). The sidewall test section (located $2 \mathrm{~cm}$ from the driven end wall) has 8 ports for optical and pressure measurements. The test pressure was monitored by a piezoelectric pressure transducer (Kistler 603B1). Five PCB $113 \mathrm{~B} 26$ transducers connected to four time-interval counters (Agilent 53220A) placed along the last $1.5 \mathrm{~m}$ of the driven section measured the incident shock velocities. Temperature $\left(\mathrm{T}_{5}\right)$ and pressure $\left(\mathrm{P}_{5}\right)$ in the reflected shock region were calculated based on the extrapolated end wall incident shock velocity with uncertainties estimated to be less than $\pm 1.5 \%$ [47].

Mixtures of research grade gases from Air Liquide $\left(\mathrm{O}_{2}\right.$, Ar, >99.999\%) and DIPK (Acros Organics, 98\%) were prepared in a heated (423 K), magnetically stirred, 33 L stainless steel mixing tank using the partial pressures of individual components and mixed for a minimum of 6 hours before experiments.

\subsection{Ignition and Species Diagnostics}

For this study, the ignition delay time was determined as the time between the midpoint of the pressure trace (caused by arrival of reflected shock wave), as recorded by the Kistler to the midpoint of the 
emissions rise (during ignition), detected by a Thorlabs PDA25K photodetector with a $430 \mathrm{~nm}$ bandpass filter to isolate the $\mathrm{CH}^{*}$ emission. the intensity of $\mathrm{OH}^{*}$ or $\mathrm{CH}^{*}$ chemiluminescence is used to measure the heat release in the flame. For this paper, the rise of $\mathrm{CH}$ was used as the start of ignition. The $\mathrm{CH}$ trace was normalized to the peak voltage measured.

An example of the ignition delay time is shown in Fig. 1 including normalized $\mathrm{CH}^{*}$ emission detection as well as the pressure trace. A slit was placed in front of the detector to limit the special resolution of the emission trace and improve the accuracy of the measurement [47].

The methane time-histories during pyrolysis were measured using cw laser absorption spectroscopy. A distributed feedback interband cascade laser centered at $3403 \mathrm{~nm}$ from Nanoplus was used in conjunction with two Boston Electronic PVI-2TR-3.4 photodetectors (described in [47]). A differential peak-valley wavelength method (corresponds to the $\mathrm{P}(8)$ line of methane v3 band [48]) was used to eliminate the interfering species during the experiments. Using this absorbance line and the $4 \mathrm{~nm}$ tuning range of the laser, an interference-free peak-valley absorption scheme was developed.

The method utilized to measure the methane time-histories is based on the Beer-Lambert Law (Eqn. 1) which relates the ratio of transmitted light to a reference $\left(\mathrm{I}_{\mathrm{tr}} / \mathrm{I}_{\mathrm{ref}}\right)$, to the absorption cross$\operatorname{section}(\sigma)$, pressure $\left(\mathrm{P}_{\text {tot }}\right)$, temperature $(\mathrm{T})$, mole fraction $(X)$, and path length $(\mathrm{L})$ :

$$
-\ln \left(\frac{I_{t r}}{I_{r e f}}\right)_{v}=\sigma(v, T, P) \frac{P_{t o t}}{R T} \chi L
$$

In order to eliminate the interference, a peak $(3403.40 \mathrm{~nm})$-valley $(3403.56 \mathrm{~nm})$ wavelength absorption scheme is used which refers to subtraction of the two transmission measurements obtained at two different wavelengths. Since the combustion products have constant absorption characteristics in the region around $3403 \mathrm{~nm}[35,46,49]$, the absorption of such species is removed by performing two sequential measurements, one at the peak absorbance of methane and the other one at its valley. Interfering species are then removed by subtracting the valley measurement from the peak to obtain the differential methane absorbance. 
Figure 1- Ignition delay time data in $1 \% \mathrm{DIPK}+20 \% \mathrm{O}_{2}+79 \% \mathrm{Ar}$ mixture $(1196 \mathrm{~K}, 0.97 \mathrm{~atm})$

The ignition delay times were measured during the oxidation of DIPK for equivalence ratios between 0.5 and 2.0. Current experiments were conducted for temperature range of 1100-1600 K at pressures of 1 and 6 atm. Fuel concentrations for these experiments ranged between 1-2\% with oxygen concentrations of $10-20 \%$. For all mixtures the oxidation was performed in an argon bath. Methane time histories were measured during DIPK pyrolysis for temperatures at 1300 and $1400 \mathrm{~K}$ for $1 \mathrm{~atm}$. Ignition delay measurements were taken for four mixtures covering the range of conditions which are summarized in Table 1. Guided by a design of experiments analysis, the broad test matrix was chosen to maximize the ranges of variations in parameters that affect ignition as it is impossible to conduct parametric studies covering all possible ranges.

Table 1- Experimental condition in shock tube

\section{Chemical kinetic model development using reaction class approach}

The reaction class approach was used to develop a kinetic mechanism for DIPK valid at high temperatures. A detailed high temperature (HT) reaction mechanism with the important reaction classes was created and then the rate constants were assigned based on analogy to the similar reactions or literature recommendations. This procedure was successfully applied for butanol combustion modeling by Sarathy et al.[42, 43] The DIPK submechanism was then integrated into a recently published AramcoMech-1.3 $\mathrm{C}_{0}-\mathrm{C}_{4}$ mechanism established by NUI-Galway [50]. The corresponding thermodynamic properties for the fuel and primary fuel radical species were calculated using the THERM [51] program. The high temperature oxidation submechanism includes unimolecular fuel decomposition, $\mathrm{H}$-abstraction reactions and decomposition and isomerization of the resulting fuel radicals.

The ignition delay behind the reflected shock waves was simulated using a zero-dimensional model with constrained volume and adiabatic boundary, solving energy equation in CHEMKIN-PRO 
[52]. This assumption is valid for short test times and for moderate heat release until ignition in shock tubes [53]. The HT reaction submechanism developed as well as the method of obtaining the rate constants through the reaction class approach for important reaction classes are explained in the following sections.

\subsection{Unimolecular fuel decomposition reactions}

The fuel unimolecular decomposition reactions are the fuel consumption reactions in high temperature region which are also denoted as initiation reactions. There are two possible classes of unimolecular decomposition for DIPK, including bond scission and $\mathrm{H}$ atom elimination which result in the formation of alkyl radicals or one hydrogen atom respectively (Sheme 1). The rate constants are considered for recombination reactions which are listed below

….............................. The rate constants for

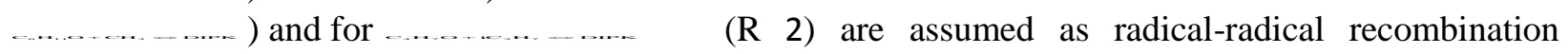

reaction based on Tsang recommendation for the recombination of n-propyl radical with methyl [54] and acetyl with isopropyl [55]. The former reaction rate constant for DIPK decomposition is assigned to be $6.0 \times 10^{15} T^{-0.32} s^{-1}$, with A-factor multiplied by 30 based on comparisons with present $\mathrm{CH}_{4}$ timehistories data. Note that in the absence of experimental data, our estimation is justified because the reaction rate constants are all assigned based on analogy of the structures with the literature recommendations for alkanes (here we used Tsang's recommendation for a ketone with $\mathrm{C}=\mathrm{O}$ functional group which can have a different decomposition reaction rate than alkanes).

The reaction rate can be rationalized by the presence of the carbonyl group which is polar compared to alkanes (The details are given in section 4.3). The rate constants for H-atom recombination with the fuel primary and tertiary radicals, namely (R3) and (R4) are assigned based on the radical recombination recommended by Allara and Shaw [56]. The modifications are made on the unimolecular decomposition rate constant according to the experimental data. 


$$
\begin{aligned}
& \mathrm{C}_{6} \mathrm{H}_{11} \mathrm{O}+\mathrm{CH}_{3} \Leftrightarrow \text { DIPK } \\
& \mathrm{C}_{4} \mathrm{H}_{7} \mathrm{O}+\mathrm{iC}_{3} \mathrm{H}_{7} \Leftrightarrow \text { DIPK } \\
& \mathrm{R}_{\text {Pri }}+\mathrm{H} \Leftrightarrow \text { DIPK } \\
& \mathrm{R}_{\text {Tert }}+\mathrm{H} \Leftrightarrow \text { DIPK }
\end{aligned}
$$

\section{Scheme 1-DIPK decomposition}

\subsection{Fuel H-atom abstraction reactions}

$\mathrm{H}$ atom abstraction takes place at primary $(\beta)$ and tertiary sites $(\alpha)$ of DIPK which results in the formation of two different fuel radicals, denoted as $R_{\text {Pri }}$ and $R_{\text {Tert }}$ (scheme 2). The hydrogen atom is abstracted from DIPK by different radicals ( $(\dot{\mathrm{R}})$ including $\mathrm{H}, \mathrm{OH}, \mathrm{HO}_{2}, \mathrm{CH}_{3}$ and $\mathrm{C}_{2} \mathrm{H}_{5}$.

\section{Scheme 2- DIPK radicals- tertiary and primary radicals}

The rate constants of abstraction from $\beta$ site by $\mathrm{H}, \mathrm{CH}_{3}$ and $\mathrm{C}_{2} \mathrm{H}_{5}$, (namely $\mathrm{R} 5$, and $\mathrm{R} 13$ ) respectively), are considered to be analogous to twice of the corresponding reaction rates of abstraction from 3-pentanone and the rate constant for (R11) is assigned with A-factor of 4 times of the corresponding recation in 3-pentanone [31]. The reaction rate for abstraction by $\mathrm{HO}_{2}$ from DIPK primary $\beta$ hydrogen, (R7), is obtained twice of isopropyl methyl ketone (iPMK) based on ab-initio and chemical kinetic study of abstraction reactions by Mendes et. al [57]. The schematic structure of iPMK is shown in Scheme 3. 
Scheme 3- Isopropyl methyl ketone iPMK

The $\mathrm{OH}$ reaction rate constants for four hexanone isomers were compared. In this study Badra et al. [58] showed that the carbonyl group position in the hexanone isomers has negligible effect on the rate constants. In the current study, we tried to use this concept to estimate the rate constants for $\mathrm{DIPK}+\mathrm{OH} \rightarrow$ products, along with Cohen's method $[59,60]$ of next-nearest-neighbor $(\mathrm{NNN})$ to specify the site specific rate constants for primary and tertiary abstracted H. For this purpose, as our first approach, according to Badra et al. [58] conclusion for hexanone isomers, we assumed that the overall reaction rate of $\mathrm{OH}$ with isopropyl methyl ketone (iPMK) is approximately the same as its isomer, 3pentanone. Now DIPK, iPMK and 3-pentanone are defined using NNN method.

$$
\begin{aligned}
& k_{\mathrm{DIPK}+\mathrm{OH}}=12 P_{2, C O}+2 T_{100, C O} \\
& k_{\mathrm{iPMK}+\mathrm{OH}}=P_{1, C O}+6 P_{2, C O}+T_{100, C O} \\
& k_{3-\text { pentanonet } \mathrm{OH}}=6 P_{1}+4 S_{10, C O}
\end{aligned}
$$

where $P_{1, C O}$ is the rate constant for the primary site $\mathrm{H}$ abstraction by $\mathrm{OH}$ next to the carbonyl group, the same as in acetone; $\boldsymbol{P}_{2, C O}$ and $\boldsymbol{T}_{100, C O}$ refers to are the rate constants for primary and tertiary $\mathrm{H}$ abstraction by $\mathrm{OH}$ from $\mathrm{CH}$ and methyl groups next to to the carbonyl group, respectively; $S_{10, C o}$ is the rate constant for secondary $\mathrm{H}$-abstraction by $\mathrm{OH}$ from $\mathrm{CH}_{2}$ nearby the carbonyl group and $P_{1}$ is the rate constant for primary $\mathrm{H}$-abstraction by $\mathrm{OH}$ from the methyl group at the site adjacent to the $\mathrm{CH}_{2}$ group based on Badra et al. [58] definitions. First, the compound isopropyl methyl ketone (iPMK) is used as a reference to estimate the rate constant for $\mathrm{H}$ - abstraction reaction from DIPK by $\mathrm{OH}$ and forming tertiary radical as a result. The reason to pick this species was due to the similar structure of tertiary carbon in iPMK with DIPK. In a recent quantum chemical calculations on ketones $\mathrm{H}$ abstraction reactions by $\mathrm{OH}$ studied by Zhou et al [61]., the rate constants for the 
reaction of $\mathrm{iPMK}$ with $\mathrm{OH}$ was estimated and the overall and the site specific reaction rate were given. We used this rate to estimate the $\mathrm{H}$ abstraction reaction for DIPK. The similar structure of the tertiary carbon in iPMK (scheme 3 in the paper) to that of DIPK was used with the corresponding branching ratio and number of tertiary sites and the reaction rate was estimated (1st approach).

Second, since Zhou et al rate constants were based on calculations, they should be verified. For that purpose, our rate estimation second approach, according to a recent study by Badra et al [58] in which the effects of the position of the carbonyl group $(\mathrm{C}=\mathrm{O})$ and methyl $(\mathrm{CH} 3)$ branching on the overall rate constant with $\mathrm{OH}$ are studied, we used the overall rate constant for 3pentanone+OH instead of $\mathrm{iPMK}+\mathrm{OH}$. Therefore, the overall rate constant of $\mathrm{DIPK}+\mathrm{OH}$ based on our estimation (equations $5.1 \& 5.2$ ) was presented.

$k_{\mathrm{DIPK}+\mathrm{OH}}=2\left(6 P_{2, \mathrm{CO}}+T_{100, \mathrm{CO}}\right)=2\left(k_{\mathrm{iPMK}+\mathrm{OH}}-P_{1, \mathrm{CO}}\right) \approx 2\left(k_{3-\mathrm{pentanone}+\mathrm{OH}}-P_{1, \mathrm{CO}}\right)$

$k_{\mathrm{DIPK}+\mathrm{OH}}=6 P_{1}+4 S_{10, \mathrm{CO}}-P_{1, \mathrm{CO}}$

The comparison which was based on next-nearest-neighbor (NNN) to specify the site specific rate constants for primary and tertiary abstracted $\mathrm{H}$ showed similar trends. Therefore, the rate constants for DIPK is first being calculated based on similar structure to 3-pentanone with NNN method as well as the analogy of the tertiary carbon with that of iPMK. 
Badra et al. [58] estimated 3-pentanone+OH reaction rate based on their calculation of $S_{10, C o}$ and $P_{1, C o}$ and verified their result by Lam et al. [36] experimental data. DIPK rate constant with OH can be estimated by analogy approach, $\left(2^{\text {nd }}\right.$ approach) which is based on using the ab initio calculation of $\mathrm{iPMK}+\mathrm{OH} \rightarrow$ products, calculated in terms of overall and site specific rates by Zhou et al. [61]. In order to estimate the rate constants for $\mathrm{H}$-abstraction reactions of DIPK with $\mathrm{O}$, resulting in primary radical, 3-pentanone reaction with $\mathrm{O}$ was considered as a reference. In order to obtain the rate for the resulting tertiary radical branching ratios for $+\mathrm{O}$ and $+\mathrm{H}$ radicals were assumed to be same. The rate constants for $\mathrm{H}$ abstraction reaction by different radicals are summarized in Table 2.

Table 2- DIPK estimated rates for $\mathrm{H}$ abstraction reactions by $\mathrm{H}, \mathrm{OH}, \mathrm{HO}_{2}, \mathrm{CH}_{3}, \mathrm{O}$ and $\mathrm{C}_{2} \mathrm{H}_{5}$ radicals

\subsection{Ketonyl radical decomposition}

The rate constants for $\mathrm{H}$ atom addition to $\mathrm{C}_{7} \mathrm{H}_{12} \mathrm{O}$ producing $\mathrm{R}_{\text {pri }}$ and $\mathrm{R}_{\text {tert }} \mathrm{C}_{7} \mathrm{H}_{12} \mathrm{O}+\mathrm{H} \Leftrightarrow \mathrm{R}_{\text {pri }} \quad(\mathrm{R} \quad 5$ $\mathrm{C}_{7} \mathrm{H}_{12} \mathrm{O}+\mathrm{H} \Leftrightarrow \mathrm{R}_{\text {tert }}$ (R 6) are assigned to have the same A-factor of $1.0 \times 10^{13} \mathrm{~cm}^{3} \mathrm{~mol}^{-1} \mathrm{~s}^{-1}$ with the activation energy of $2.9 \mathrm{kcal} / \mathrm{mol}$ and $1.2 \mathrm{kcal} / \mathrm{mol}$ respectively based on Curran et al recommendation [44]. Also the rate constants corresponding to the addition of methyl to $\mathrm{C}_{6} \mathrm{H}_{10} \mathrm{O}$ to form $\mathrm{R}_{\text {pri }}$ $\mathrm{C}_{6} \mathrm{H}_{10} \mathrm{O}+\mathrm{CH}_{3} \Leftrightarrow \mathrm{R}_{\text {pri }}$ ( $\mathrm{R} 7$ ) as well as the addition of isopropyl radical to dimethyl ketene (DMK) to produce $\mathrm{R}_{\text {tert }} \mathrm{DMK}+\mathrm{iC}_{3} \mathrm{H}_{7} \Leftrightarrow \mathrm{R}_{\text {tert }} \quad(\mathrm{R} \quad 8) \quad$ are $\quad$ estimated to be $8.5 \times 10^{10} \exp (-5334 / T) s^{-1} \cdot \mathrm{C}_{6} \mathrm{H}_{11} \mathrm{O}$ is another radical formed by a methyl group removal from the fuel. The reaction rate constants for $\mathrm{C}_{6} \mathrm{H}_{10} \mathrm{O}+\mathrm{H} \Leftrightarrow \mathrm{C}_{6} \mathrm{H}_{11} \mathrm{O}$ (R 9) and $\ldots \ldots \ldots \ldots \ldots \ldots \ldots \ldots$ ) are estimated based on similar approach to be $1.0 \times 10^{13} \exp (-1459 / T) s^{-1}$ and $8.5 \times 10^{10} \exp (-5334 / T) s^{-1}$ respectively. 


$$
\begin{aligned}
& \mathrm{C}_{7} \mathrm{H}_{12} \mathrm{O}+\mathrm{H} \Leftrightarrow \mathrm{R}_{\text {pri }} \\
& \mathrm{C}_{7} \mathrm{H}_{12} \mathrm{O}+\mathrm{H} \Leftrightarrow \mathrm{R}_{\text {tert }} \\
& \mathrm{C}_{6} \mathrm{H}_{10} \mathrm{O}+\mathrm{CH}_{3} \Leftrightarrow \mathrm{R}_{\text {pri }} \\
& \mathrm{DMK}+\mathrm{iC}_{3} \mathrm{H}_{7} \Leftrightarrow \mathrm{R}_{\text {tert }} \\
& \mathrm{C}_{6} \mathrm{H}_{10} \mathrm{O}+\mathrm{H} \Leftrightarrow \mathrm{C}_{6} \mathrm{H}_{11} \mathrm{O} \\
& \mathrm{C}_{3} \mathrm{H}_{4} \mathrm{O}+\mathrm{iC}_{3} \mathrm{H}_{7} \Leftrightarrow \mathrm{C}_{6} \mathrm{H}_{11} \mathrm{O}
\end{aligned}
$$

\subsection{Fuel radical isomerization reaction}

The isomerization reaction of fuel radicals $\mathrm{R}_{\text {pri }} \Leftrightarrow \mathrm{R}_{\text {tert }}$

based on 1,2 H-Shift (Scheme 4) rate rule used in the calculations by Matheu et al [62] is assigned to be

$$
\begin{aligned}
& 3.56 \times 10^{10} \times T^{0.88} \exp (-14897 / T) s^{-1} . \\
& \mathrm{R}_{\mathrm{pri}} \Leftrightarrow \mathrm{R}_{\text {tert }}
\end{aligned}
$$

Scheme 4- $\mathrm{H}$ atom migration in 1,2 H-Shift

\subsection{Olefin unimolecular decomposition reactions}

The radical decomposition through $\beta$-scission rule produces unsaturated species with carbon atoms double bond for which the decomposition and abstraction rate constants are to be determined. DIPK 
radicals $\beta$-scission results in the formation of $\mathrm{C}_{7} \mathrm{H}_{12} \mathrm{O}$. The unimolecular decomposition reaction of DIPK by removing a methyl group also yields $\mathrm{C}_{6} \mathrm{H}_{11} \mathrm{O}$ radical which undergoes $\beta$-scission to produce $\mathrm{C}_{6} \mathrm{H}_{10} \mathrm{O}$ and $\mathrm{H}$ radical. The rate constants of decomposition for $\mathrm{C}_{7} \mathrm{H}_{12} \mathrm{O}$ are considered in reverse direction as recombination reaction of isopropyl radical with $\mathrm{C}_{4} \mathrm{H}_{5} \mathrm{O}$ as well as $\mathrm{sC}_{3} \mathrm{H}_{5}$ and $\mathrm{C}_{4} \mathrm{H}_{7} \mathrm{O}$. The rate constant for the former is estimated to be $9.033 \times 10^{12} \times T^{-0.35} s^{-1}$ based on Tsang recommendation [54] found in NIST web book [63] for recombination of isopropyl to acetyl group. Similarly, the rate constant for $\mathrm{C}_{3} \mathrm{H}_{5}$ and acetyl radical recombination is used to estimate the $\mathrm{SC}_{3} \mathrm{H}_{5}+\mathrm{C}_{4} \mathrm{H}_{7} \mathrm{O} \Leftrightarrow \mathrm{C}_{7} \mathrm{H}_{12} \mathrm{O} \quad$ (R 13 rate constant [55]. $\mathrm{iC}_{3} \mathrm{H}_{7}+\mathrm{C}_{3} \mathrm{H}_{3} \mathrm{O} \Leftrightarrow \mathrm{C}_{6} \mathrm{H}_{10} \mathrm{O}$ (R 14) rate constant is estimated to be the same as $\mathrm{iC}_{3} \mathrm{H}_{7}+\mathrm{C}_{4} \mathrm{H}_{5} \mathrm{O} \Leftrightarrow \mathrm{C}_{7} \mathrm{H}_{12} \mathrm{O} \quad$ (R 12).

$$
\begin{aligned}
& \mathrm{iC}_{3} \mathrm{H}_{7}+\mathrm{C}_{4} \mathrm{H}_{5} \mathrm{O} \Leftrightarrow \mathrm{C}_{7} \mathrm{H}_{12} \mathrm{O} \\
& \mathrm{sC}_{3} \mathrm{H}_{5}+\mathrm{C}_{4} \mathrm{H}_{7} \mathrm{O} \Leftrightarrow \mathrm{C}_{7} \mathrm{H}_{12} \mathrm{O} \\
& \mathrm{iC}_{3} \mathrm{H}_{7}+\mathrm{C}_{3} \mathrm{H}_{3} \mathrm{O} \Leftrightarrow \mathrm{C}_{6} \mathrm{H}_{10} \mathrm{O}
\end{aligned}
$$

\subsection{Olefin H-abstraction reaction}

The $\mathrm{H}$ abstraction from large olefins $\left(>\mathrm{C}_{4}\right)$ formed during DIPK oxidation are assumed to occur either in paraffinic side or double bond carbon side, although the latter has smaller effects on the large molecule [64]. Therefore, in $\mathrm{C}_{7} \mathrm{H}_{12} \mathrm{O}$, the $\mathrm{H}$ abstraction reactions are from allylic and vinyl sites as well as primary and tertiary positions (see 
Scheme 5). The rate constants for the $\mathrm{H}$ abstraction reactions from $\mathrm{C}_{7} \mathrm{H}_{12} \mathrm{O}$ paraffinic side by all the radicals considered here $\mathrm{C}_{7} \mathrm{H}_{12} \mathrm{O}+\mathrm{H} \Leftrightarrow \mathrm{C}_{7} \mathrm{H}_{11} \mathrm{O}+\mathrm{H}_{2} \quad$ (R 15) to (R 17)

are half of that of DIPK in order to form primary and tertiary radicals.

The rate constant for the $\mathrm{H}$ abstraction by $\mathrm{H}$ atom from vinyl site is assigned to be $5.06 \times 10^{7} \times T^{1.98} \exp (-5910 / T) s^{-1}$ based on group additivity rate calculation by Sumathi et al. [65] for $\mathrm{R}_{2} \mathrm{C}=\mathrm{CH}_{2}+\mathrm{H} \rightarrow \mathrm{R}_{2} \mathrm{C}=\dot{\mathrm{C}} \mathrm{H}+\mathrm{H}_{2}$. Similarly, from the same reference, the rate of abstraction from allylic site is assumed to be $1.299 \times 10^{6} \times T^{2.38} \exp (-1410 / T) \mathrm{s}^{-1}$ predicted for $\mathrm{R}_{2} \mathrm{C}=\mathrm{CRCH}_{3}+\mathrm{H} \rightarrow \mathrm{R}_{2} \mathrm{C}=\mathrm{CRCH}_{2}+\mathrm{H}_{2}$. The $\mathrm{H}$ abstraction reaction rate of $\mathrm{C}_{7} \mathrm{H}_{12} \mathrm{O}$ by $\mathrm{OH}$ to from vinyl site is estimated by similarity to that of 2-butene-2-one reaction measured by Badra $e t$ al. [41] to be $8.513 \times 10^{12} \times \exp (-4666 / T) s^{-1}$. The rest of the rate constants including the abstraction reactions by $\mathrm{CH}_{3}$ and $\mathrm{HO}_{2}$ are assumed to be similar to isobutene $\mathrm{H}$ abstraction, [66] resulting in vinyl and allylic radicals, as found in the latest version of isooctane reaction mechanism [67]. In the reactions $\mathrm{C}_{7} \mathrm{H}_{12} \mathrm{O}+\mathrm{H} \Leftrightarrow \mathrm{C}_{7} \mathrm{H}_{11} \mathrm{O}+\mathrm{H}_{2} \quad$ (R 15) to $\mathrm{C}_{7} \mathrm{H}_{12} \mathrm{O}+\mathrm{CH}_{3} \Leftrightarrow \mathrm{C}_{7} \mathrm{H}_{11} \mathrm{O}+\mathrm{CH}_{4} \quad$ (R 18), $\mathrm{C}_{7} \mathrm{H}_{11} \mathrm{O}$ stands for the general representation of all radicals (allylic, vinyl, primary and tertiary).

Scheme 5- $\mathrm{H}$ abstraction from $\mathrm{C}_{7} \mathrm{H}_{12} \mathrm{O}$

$$
\begin{aligned}
& \mathrm{C}_{7} \mathrm{H}_{12} \mathrm{O}+\mathrm{H} \Leftrightarrow \mathrm{C}_{7} \mathrm{H}_{11} \mathrm{O}+\mathrm{H}_{2} \\
& \mathrm{C}_{7} \mathrm{H}_{12} \mathrm{O}+\mathrm{OH} \Leftrightarrow \mathrm{C}_{7} \mathrm{H}_{11} \mathrm{O}+\mathrm{H}_{2} \mathrm{O} \\
& \mathrm{C}_{7} \mathrm{H}_{12} \mathrm{O}+\mathrm{HO}_{2} \Leftrightarrow \mathrm{C}_{7} \mathrm{H}_{11} \mathrm{O}+\mathrm{H}_{2} \mathrm{O}_{2} \\
& \mathrm{C}_{7} \mathrm{H}_{12} \mathrm{O}+\mathrm{CH}_{3} \Leftrightarrow \mathrm{C}_{7} \mathrm{H}_{11} \mathrm{O}+\mathrm{CH}_{4}
\end{aligned}
$$




\subsection{Olefin radical isomerization reaction}

As mentioned in the previous section, there are four different radicals formed from $\mathrm{C}_{7} \mathrm{H}_{12} \mathrm{O}$ in $\mathrm{H}$ abstraction reactions. The isomerization rate constants are estimated for 1,3 $\mathrm{H}$-shift from vinyl to form allylic radical $(\mathrm{v} \rightarrow \mathrm{a})$ as well as $1,2 \mathrm{H}$-shift from primary to form tertiary radical $(\mathrm{p} \rightarrow \mathrm{t})$ to be $3.80 \times 10^{10} \times T^{0.67} \exp (-19476 / T) s^{-1}$ and $3.56 \times 10^{10} \times T^{0.88} \exp (-14897 / T) s^{-1}$ respectively based on Matheu et al. [62] calculations.

$$
\begin{gathered}
\mathrm{C}_{7} \mathrm{H}_{11} \mathrm{O}(\mathrm{v}) \Leftrightarrow \mathrm{C}_{7} \mathrm{H}_{11} \mathrm{O}(\mathrm{a}) \\
\mathrm{C}_{7} \mathrm{H}_{11} \mathrm{O}(\mathrm{p}) \Leftrightarrow \mathrm{C}_{7} \mathrm{H}_{11} \mathrm{O}(\mathrm{t})
\end{gathered}
$$

\subsection{Olefin radical decomposition reaction}

The decomposition rate constants for radicals are estimated in reverse direction. It is assumed that all the radicals decompose to smaller species for which the rate constants are all $2.5 \times 10^{13} \times \exp (-22647 / T) s^{-1}$ based on Curran et al. [64].

$$
\begin{aligned}
& \mathrm{C}_{7} \mathrm{H}_{11} \mathrm{O}(\mathrm{v}) \Leftrightarrow \mathrm{pC}_{3} \mathrm{H}_{4}+\mathrm{C}_{4} \mathrm{H}_{7} \mathrm{O} \\
& \mathrm{C}_{7} \mathrm{H}_{11} \mathrm{O}(\mathrm{a}) \Leftrightarrow \mathrm{aC}_{3} \mathrm{H}_{4}+\mathrm{C}_{4} \mathrm{H}_{7} \mathrm{O} \\
& \mathrm{C}_{7} \mathrm{H}_{11} \mathrm{O}(\mathrm{t}) \Leftrightarrow \mathrm{DMK}+\mathrm{sC}_{3} \mathrm{H}_{5} \\
& \mathrm{C}_{7} \mathrm{H}_{11} \mathrm{O}(\mathrm{p}) \Leftrightarrow \mathrm{C}_{4} \mathrm{H}_{5} \mathrm{O}+\mathrm{C}_{3} \mathrm{H}_{6}
\end{aligned}
$$




\subsection{Keto-enol tautomerization}

Ketones are often in rapid equilibrium with their tautomeric form, known as an enol. The isomerization called keto-enol tautomerization in which the hydrogen in $\alpha$ position (next to the carbonyl group) moves to form the hydroxyl group by shifting the double bond from the carbonyl group to the carbon atoms bond next to the $\mathrm{OH}$ moiety. As the concerted keto-enol tautomerization is constrained by the transition state geometry requirements, an acid or a base catalysis is required for tautomerization to take place. This kind of reaction usually occurs in favor of ketone formation which is more stable species. Sarathy et al. [43] estimated the rate constant for butanol isomers enol-keto tautomerization catalyzed by $\mathrm{H}, \mathrm{HO}_{2}$ and formic acid. In order to estimate the rate constant for this type of reaction, supplementary information is required which is not available at the moment.

The reaction mechanism for high temperature region is developed and presented. Some of the reaction rates are modified based on the experimental validation which is explained in the Result and discussions section.

\section{Results and discussion}

\subsection{Ignition delay times}

The ignition delay time data points for each of these conditions are illustrated in Fig. 2. The proposed kinetic model was used to simulate the ignition delay time and the results are compared to the experimental data from UCF's shock tube. The effect of reactants various fractions on the reactivity of DIPK is studied by comparing the ignition delay time versus temperature inverse at different equivalence ratios and at the pressures of 1 and 6 atm. The shock tube experimental conditions are presented in Table 1 and the results of the experiments are summarized in Table 3. The results displayed in Fig. 3 show good agreement between the simulation (solid lines) and experiment (markers) for the given temperature ranges. The results are also compared with the reaction mechanism developed by Allen et al. [14] (dashed lines). The discrepancies are observed between the simulation based on their mechanism and the 
experimental data. In comparison, the model used in the current work improved the prediction by about an order of magnitude.

Figure 2- Current ignition delay time results for DIPK oxidation

In addition to the comparisons to the updated kinetic model, a correlation was developed to predict the ignition delay times using the temperature, pressure, fuel concentration and oxygen concentration, with $R^{2}=0.979$. Equation (6) shows the correlation:

$$
\begin{aligned}
& \tau_{i g n}[\mu s]=A \exp \left(\frac{E[\mathrm{cal} / \mathrm{mol}]}{R[\mathrm{cal} / \mathrm{mol} \cdot \mathrm{K}] T[K]}\right) P^{b}[\mathrm{DIPK}]^{c}\left[O_{2}\right]^{d} \\
& =1.97 \cdot \exp \left(\frac{28196.2}{R T}\right) P^{-1.08}[\mathrm{DIPK}]^{-0.29}\left[O_{2}\right]^{-1.93}
\end{aligned}
$$

where $A$ had an uncertainty of $\pm 0.63, E$ had an uncertainty of \pm 1262.82 , the uncertainty of $b$ was \pm 0.08 , the uncertainty of $c$ was \pm 0.09 and the uncertainty of $d$ was \pm 0.14 . From the correlation and the uncertainty in the various measurements, the overall uncertainty in the ignition delay time was determined to be less than $18 \%$.

The uncertainty was determined using a combination of the correlation presented above and the uncertainty of the pressure and temperature in the test section. Using the linear regression analysis described in Bevington and Robinson, the velocity at the end wall was determined from the four timercounters [68]. From this analysis, the end wall velocity was determined to be less than $1 \%$. The next part in determining the uncertainty in the ignition delay times is to calculate the uncertainty in the pressure and temperature. From the Nishida et al., the pressure and temperature for the test section can be written in terms of the initial pressure and temperature and the end wall velocity [69]. The uncertainty in the temperature and the pressure can then be determined to be $2 \%$ for each value. The uncertainty in ignition delay times was calculated from the uncertainty analysis on the ignition delay time correlation and factoring in the values for the uncertainty for each measurement from the specs 
and the uncertainties from the nonlinear regression analysis from the correlation as well as the linear regression analysis used to calculate the uncertainty in the pressure and temperature of the system.

Figure 3- Simulated (solid lines, present mechanism) and experimental (markers) ignition delay times for different mixtures (Table 1) of DIPK oxidation; the results are compared to Allen et al mechanism [14] (dashed lines).

Figure 4- Current ignition delay times (experimental and simulations) as a function of pressures for DIPK oxidation in Ar bath at $\varphi=1$ (reactants percentages are given in Table 1). Note: 10atm data are from [14].

Table 3- The experimental ignition delay time results for different mixtures

The pressure effects on ignition delay time is shown at the different reactants ratios and at pressures of 1 , 6 and 10 atm in Fig. 4. In order to simulate the ignition delay time at high pressure, the experimental pressure trace profile was used in CHEMKIN-PRO.

Figure 4 shows the experimental ignition delay time at different pressures compared to the present model. Pressure increases reactivity significantly (1 to $6 \mathrm{~atm})$ and this compensates for reduced reactivity caused by decreasing $\mathrm{O}_{2}$ concentration (the mixture fractions are also changed from $20 \% \mathrm{O}_{2}$ to $10 \%$.). This 
shows that the oxidizer concentration effects are significant such that the increased reactivity due to the increased pressure is compensated by the reduced amount of $\mathrm{O}_{2}$ concentration.

\subsection{DIPK oxidation path analysis}

The model based on the reaction class approach was validated by experimental data; therefore, it has been used to describe DIPK high temperature oxidation pathways (Fig. 5). The pathways are presented based on the CHEMKIN-PRO zero-dimensional model for 2\% DIPK oxidation in Ar at $1300 \mathrm{~K}$ at time at which $20 \%$ of the fuel is consumed. The consumption of DIPK is initiated through Habstraction reactions resulting in the formation of primary and tertiary radicals. Furthermore, DIPK is consumed through the unimolecular decomposition reactions. The decomposition pathway resulting in methyl radical and $\mathrm{C}_{6} \mathrm{H}_{11} \mathrm{O}$ is considered as a dominant reaction controlling the fuel reactivity. In addition, due to the formation of $\mathrm{CH}_{3}$ which is a source of methane, it is also important in $\mathrm{CH}_{4}$ sensitivity analysis.

The fuel radicals from the $\mathrm{H}$-abstraction reactions decompose to propene (from the $\mathrm{R}_{\text {pri }}$ ) and dimethyl ketene (from $\mathrm{R}_{\text {tert }}$ ). The radicals decomposition also results in formation of an important intermediate, $\mathrm{C}_{7} \mathrm{H}_{12} \mathrm{O}$ which can further decompose through unimolecular decomposition or participate in $\mathrm{H}$-abstraction reactions which forms four different radicals. The isomerization reactions between these radicals are also considered within the pathway.

Figure 5- Oxidation path analysis for 2\% DIPK in $\mathrm{Ar} / \mathrm{O}_{2}(\varphi=1)$ at $1300 \mathrm{~K}, 1 \mathrm{~atm}$. 


\subsection{Methane time-histories}

Methane is one of the main products in ketones oxidation. The laser absorption spectroscopy was performed using a differential absorption scheme. The peak wavelength $(3403.40 \mathrm{~nm})$ for methane was determined by Pyun et al. [49]. In this study, we noticed that the valley wavelength of 3403.7 that was used in the previous paper had more interference than previously measured in our lab [47]. Therefore, a new valley wavelength was chosen in order to reduce the noise and increase the accuracy of the measurement. A new wavelength was chosen of $3403.56 \mathrm{~nm}$ that is closer to the original wavelength and has a smaller differential absorption cross section as shown in Fig. 6. Possible interfering species and their cross section is also provided in Fig. 6.

Methane time-histories were measured at 1300 and $1400 \mathrm{~K}$. Because of the smaller differential absorption cross section of methane, the measurement window was limited to a narrow temperature region. During the breakdown of DIPK, methane is produced as an intermediate specie (Fig. 7). Thus, these time-histories serve as a secondary method for the validation of chemical kinetic modeling and help to optimize the DIPK decomposition reaction rates [45].

Figure 6- Methane, $\mathrm{H} 2 \mathrm{O}, \mathrm{OH}$ and DIPK Absorptions at the peak and valley measurements and most common interfering species.

Figure 7- Measured $\mathrm{CH}_{4}$ concentration profiles during DIPK pyrolysis in Ar at 1300 and $1400 \mathrm{~K}$.

Figure 8- $\mathrm{CH}_{4}$ Absorption at both the peak and the valley wavelengths at $1300 \mathrm{~K}$. Absorbance (left axis) and pressure (right axis).

To calculate the methane mole fractions, the absorption at the peak and valley were subtracted from each other to determine the differential absorbance. For the new wavelength, the differential cross section was measured for the range of temperatures considered. Equation 7 shows how the methane mole fraction was calculated from the Beer-Lambert Law and the differential absorbance: 


$$
\chi_{\mathrm{CH}_{4}}=\frac{\left(\alpha_{\mathrm{CH}_{4}, \text { peak }}-\alpha_{\mathrm{CH}_{4}, \text { valley }}\right)}{\frac{\left(\sigma_{\mathrm{CH}_{4}, \text { peak }}-\sigma_{\mathrm{CH}_{4}, \text { valley }}\right) P_{\text {tot }} L}{R T}}
$$

An example of the peak and valley absorbance measurements is shown in Figure 8. It shows that without eliminating the interference, the methane concentration would not be determined as the measured profiles at these wavelengths differ significantly.

Figure 9- $\mathrm{CH}_{4}$ concentration profiles during 2\% DIPK pyrolysis in $\mathrm{Ar}$ at $1300 \mathrm{~K}$ (top) and $1400 \mathrm{~K}$ (bottom) compared to the present HT mechanism as well as Allen et al. mechanism [14] at 0.9 bar.

The current HT DIPK reaction mechanism is used to simulate $\mathrm{CH}_{4}$ concentration time-histories (results for 2\% DIPK pyrolysis in argon are shown in Fig. 9). At 1400K, there is rapid formation of methane compared to the slower rise at $1300 \mathrm{~K}$ which is captured by the present mechanism. Also, one can seen a decent quantitative agreement with current mechanism simulation at $1300 \mathrm{~K}$, while the Allen et al. [14] mechanism (dashed lines) slightly under-predicts current data during all times. At 1400K, the present model reasonably predicts the measured profile up to $650 \mu \mathrm{s}$, and underpredicts the data for later times. The predicted profiles by the Allen et al. shows a reverse trend: good agreement at later times and underprediction the early-time rise. A temperature sensitivity analysis for $\mathrm{CH}_{4}$ profiles (using $\mathrm{CHEMKIN}$ PRO, see equation 8) identified the most sensitive reaction under these conditions to be the primary radical $\beta$-scission, which results in the formation of $\mathrm{CH}_{3}$ and $\mathrm{C}_{6} \mathrm{H}_{10} \mathrm{O}-1$. In addition, the tertiary radical $\beta$ scission turned out to be the second most sensitive reaction. In the absence of experimental data for the rate constants of DIPK main reactions, better agreement between predictions and experiment can be achieved by detailed investigations based on quantum chemical calculations on the rate constants of the reactions R11, R12, the group of the reaction associated with $\mathrm{R} 28$ and the reaction of $\mathrm{C}_{3} \mathrm{H}_{4} \mathrm{O}+\mathrm{CH}_{3} \rightarrow \mathrm{C}_{3} \mathrm{H}_{3} \mathrm{O}+\mathrm{CH}_{4}$, all of which also appear in the temperature sensitivity analysis.

\subsection{Sensitivity analysis}


The $\mathrm{OH}$ concentration ignition delay time sensitivity analysis has been performed to identify the most sensitive reactions in the oxidation of DIPK using CHEMKIN-PRO, where the sensitivity coefficient $(\mathrm{S})$ for $\mathrm{i}^{\text {th }}$ reaction rate $\left(\mathrm{k}_{\mathrm{i}}\right)$ for a species is defined as,

$$
S\left(X_{\text {species, }} k_{i}, t\right)=\left\{\frac{d X_{\text {species }}(t)}{d k_{i}}\right\}\left\{\frac{k_{i}}{X_{\text {species }}(t)}\right\}
$$

The analysis is based on $\mathrm{OH}$ radical concentration and implemented for $2 \%$ DIPK with $20 \% \mathrm{O}_{2}$ in Ar bath at $1100 \mathrm{~K}$ and $1 \mathrm{~atm}$. The result is illustrated in Fig. 10 where the two important reactions are shown with red arrows. These reactions are $\mathrm{H}$-abstraction reaction from DIPK by $\mathrm{H}$ atom resulting in the formation of tertiary radical, as well as DIPK unimolecular decomposition to methyl group and $\mathrm{C}_{6} \mathrm{H}_{11} \mathrm{O}$. Both reactions are considered as the main consumption pathways of DIPK and found to have high sensitivity in controlling the reactivity. These reaction rates were adjusted such that improved agreement between the simulation and experimental data was attained.

Figure 10- Ignition delay time sensitivity analysis for $2 \%$ DIPK in $\mathrm{Ar} / \mathrm{O}_{2}(\varphi=1)$ at $1100 \mathrm{~K}$ and 1 atm using the CHEMKIN-PRO tool at the time of $20 \%$ fuel consumption.

Figure 11- $\mathrm{CH}_{4}$ sensitivity analysis at $1400 \mathrm{~K}$ and 0.9 for $2 \%$ DIPK in Ar.

The $\mathrm{CH}_{4}$ sensitivity analysis (Fig. 11) was performed to show the most sensitive reactions for pyrolysis. The $\mathrm{H}$-abstraction from DIPK by $\mathrm{CH}_{3}$ radical which results in the formation of $\mathrm{CH}_{4}$ and fuel radicals, were two of the most sensitive reactions. The A-factor sensitivity also reveals that DIPK decomposition reaction to $\mathrm{CH}_{3}+\mathrm{C}_{6} \mathrm{H}_{11} \mathrm{O}$ was one of the most sensitive reactions. In addition, $\mathrm{C}_{6} \mathrm{H}_{11} \mathrm{O}$ decomposition to $\mathrm{C}_{3} \mathrm{H}_{4} \mathrm{O}+\mathrm{iC}_{3} \mathrm{H}_{7}$ was an important reaction. As mentioned previously, Curran's recommendation [44] for $\left(\mathrm{CH}_{3}+\right.$ alkyl $=$ fuel $)$ to estimate the rate constant for $\mathrm{CH}_{3}+\mathrm{C}_{6} \mathrm{H}_{11} \mathrm{O}=$ DIPK is apparently too low. This reaction is also very important source of methane since it produces methyl radical which is a source of methane production (current experiments). Also the rate constant for this specific reaction was found to 
play a crucial role in determination of ignition time. In the absence of direct experimental or theoretical study, present experimental data has been used as a validation method and these sensitive reaction rates were adjusted (as we described in earlier sections).

Detailed quantum chemical and experimental investigations of fuel specific decomposition and abstraction reactions of large ketones are recommended for future study.

\section{Conclusion}

A high-temperature (HT) chemical kinetic model was developed and validated against new shock tube experimental data for di-isopropyl ketone. The HT model developed using the reaction class approach showed significant improvements over that developed by Allen et al. [14] using an automated approach. Specifically shock tube ignition delay time and methane concentration from DIPK pyrolysis were accurately captured by the present model. The new mechanism shows reasonable agreement with the ignition delay times at high temperatures. The reaction path analysis as well as the $\mathrm{OH}$ sensitivity were performed and the oxidation of DIPK were discussed along with the most sensitive reactions which control the fuel reactivity. A correlation was developed based on the experimental data to predict the ignition delay times as a function of reactants concentration, temperature, and pressure. To the best of our knowledge, current ignition delay times (above $1050 \mathrm{~K}$ ) and methane time-histories are the first such experiments performed in DIPK- an important biofuel candidate.

In order to further validate and optimize the new mechanism, additional experiments are planned over a greater range of experimental conditions and extending time-histories to different intermediate species (e.g., $\mathrm{CO}, \mathrm{C}_{2} \mathrm{H}_{4}, \mathrm{CO}_{2}$ ). Also, direct experimental and theoretical studies of key abstraction and decompsitions reactions of DIPK are recommended for future study. The experimental data and mechanism presented in this paper could greatly improve the decision making required for using DIPK as a biofuel in advanced engines.

\section{Acknowledgments}


Research at UCF was supported by financial assistance from the Mechanical and Aerospace Department, Florida Space Institute, and competitive research funding from the King Abdullah University of Science and Technology (KAUST). The authors thank Joseph Lopez and Leigh Nash for help with the shock tube experiments. Acknowledgement is made to the donors of the American Chemical Society Petroleum Research Fund and Department of Energy (grant number: DE-FE0025260) for partial financial support. Finally we would like to acknowledge the useful suggestions made by the anonymous reviewers for considerably improving this paper.

\section{References}

[1] USEIA, U. S. Energy Information Administration, International Energy Outlook, http://www.eia.gov/forecasts/ieo/pdf/0484(2011).pdf, (2011).

[2] M.A. Rude, A. Schirmer, New microbial fuels: a biotech perspective, Current Opinion in Microbiology 12 (2009) 274-281.

[3] K. Kohse-Hoinghaus, P. Oßwald, T.A. Cool, T. Kasper, N. Hansen, F. Qi, C.K. Westbrook, P.R. Westmoreland, Biofuel Combustion Chemistry: From Ethanol to Biodiesel Angew. Chem. Int. Ed. 49 (2010) 3572-3598.

[4] T. Liu, C. Khosla, Genetic Engineering of Escherichia coli for Biofuel Production, Annu. Rev. Genet. 44 (2010) 53-69.

[5] S. Chu, A. Majumdar, Opportunities and challenges for a sustainable energy future, Nature 488 (2012) 294-303.

[6] P.P. Peralta-Yahya, F. Zhang, S.B.d. Cardayre, J.D. Keasling, Microbial engineering for the production of advanced biofuels, Nature 488 (2012) 320-328.

[7] P.S. Veloo, Dagaut, P., Togbe, C., Dayma, G., Sarathy, S. M., Westbrook, C. K., \& Egolfopoulos, F. N., Jet-stirred reactor and flame studies of propanal oxidation, Proceedings of the Combustion Institute 34(1) (2013) 599-606.

[8] P.S. Veloo, Dagaut, P., Togbé, C., Dayma, G., Sarathy, S. M., Westbrook, C. K., \& Egolfopoulos, F. N. , Experimental and modeling study of the oxidation of n-and iso-butanal, Combustion and Flame 160(9) (2013) 1609-1626.

[9] G. Barari, B. Koroglu, A. Masunov, S.S. Vasu, Products and pathways of aldehydes oxidation in the negative temperature coefficient region, J. of Energy Resources TechnologyTransactions of the ASME 139 (2016) 012203.

[10] M. Stadler, B. Schulz, High energy biofuel from endophytic fungi?, Trends in Plant Science 14 (2009) 353-355.

[11] M.A. Griffin, D.J. Spakowicz, T.A. Gianoulis, S.A. Strobel, Volatile organic compound production by organisms in the genus Ascocoryne and a re-evaluation of myco-diesel production by NRRL 0072, Microbiology 156 (2010) 3814-3829.

[12] S.K. Singh, G.A. Strobel, B. Knighton, B. Geary, J. Sears, D. Ezra, An Endophytic Phomopsis sp. Possessing Bioactivity and Fuel Potential with its Volatile Organic Compounds, Microb Ecol 61 (2011) 729-739.

[13] G.A. Strobel, B. Knighton, K. Kluck, Y. Ren, T. Livinghouse, M.A. Griffin, D.J. Spakowicz, J. Sears, Microbiology 154 (2008) 3319-3328. 
[14] J.W. Allen, A.M. Scheer, C.W. Gao, S.S. Merchant, S.S. Vasu, O. Welz, J.D. Savee, D.L. Osborn, C. Lee, S. Vranckx, Z. Wang, F. Qi, R.X. Fernandes, W.H. Green, M.Z. Hadi, C.A. Taatjes, A Coordinated Investigation of the Combustion Chemistry of Diisopropyl Ketone, a Prototype for Biofuels Produced by Endophytic Fungi, Combust. Flame 161 (2014) 711-724.

[15] J.W. Allen , C.W. Gao, Vasu S. S., Vrancx S., Fernandes R.X., W.H. Green, C.A. Taatjes, Model generation and evaluation for the oxidation of ketones, AIChE Annual Meeting, Conference Proceedings, (2012).

[16] S.S. Vasu, O. Welz, D.L. Osborn, C.A. Taatjes, Synchrotron photoionization measurements of biofuel autoignition chemistry: Low-temperature oxidation of ketones, 7th International Conference on Gas Kinetics, (2011).

[17] A.J. Janssen, F.W. Kremer, J.H. Baron, M. Muether, S. Pischinger, J. Klankermayer, TailorMade Fuels from Biomass for Homogeneous Low-Temperature Diesel Combustion, Energy \& Fuels 25 (2011) 4734-4744.

[18] M.T. Mends, E. Yu, G.A. Strobel, S. Riyaz-Ul-Hassan, E. Booth, B. Geary, J. Sears, C.A. Taatjes, M.Z. Hadi, An Endophytic Nodulisporium sp. Producing Volatile Organic Compounds Having Bioactivity and Fuel Potential., J. Pet. Environ. Biotechnol. 3 (2012) 117.

[19] M. Griffin, D. Spakowicz, T. Gianoulis, S.A. Strobel, Volatile organic compound production by organisms in the genus Ascocoryne and a re-evaluation of myco-diesel production by NRRL 50072, Microbiology 156 (2010) 3814-3829.

[20] J.M. Gladden, C.A. Taatjes, C.W. Gao, G. O'Bryan, A.J. Powell, A.M. Scheer, W. Wu, Tailoring Next-Generation Biofuels and their Combustion in Next-Generation Engines, Sandia Report 2013-10094, (2013).

[21] J.K. Lefkowitz, S.H. Won, Y. Fenard, Y. Ju, Uncertainty assessment of species measurements in acetone counterflow diffusion flames, Proceedings of the Combustion Institute 34 (2013) 813-820.

[22] C.T. Chong, S. Hochgreb, Measurements of laminar flame speeds of acetone/methane/air mixtures, Combustion and Flame 158 (2011) 490-500.

[23] S. Pichon, G. Black, N. Chaumeix, M. Yahyaoui, J.M. Simmie, H.J. Curran, R. Donohue, The combustion chemistry of a fuel tracer: Measured flame speeds and ignition delays and a detailed chemical kinetic model for the oxidation of acetone, Combustion and Flame 156 (2009) 494-504.

[24] C. Schulz, V. Sick, Tracer-LIF diagnostics: quantitative measurement of fuel concentration, temperature and fuel/air ratio in practical combustion systems, Progress in Energy and Combustion Science 31 (2005) 75-121.

[25] V. Dias, J. Vandooren, H. Jeanmart, An experimental and modeling study of the addition of acetone to $\mathrm{H} 2 / \mathrm{O} 2 / \mathrm{Ar}$ flames at low pressure, Proceedings of the Combustion Institute in press. [26] Z. Zhao, D.T. Huskey, J.M. Nicovich, P.H. Wine, Kinetics Study of the Gas-Phase Reactions of Atomic Chlorine with Acetone, 2-Butanone, and 3-Pentanone, International Journal of Chemical Kinetics 40 (2008) 259-267.

[27] G. Black, S. Pichon, H. Curran, J. Simmie, R. Donohue, N. Djebaili-Chaumeix, An Experimental and Modelling Study of the Combustion of Acetone, Third European Combustion Meeting ECM, 2007.

[28] V. Vasudevan, D.F. Davidson, R.K. Hanson, High-Temperature Measurements of the Reactions of $\mathrm{OH}$ with Toluene and Acetone, Journal of Physical Chemistry A 109 (2005) 33523359. 
[29] E.E. Dames, K.-Y. Lam, D.F. Davidson, R.K. Hanson, An improved kinetic mechanism for 3-pentanone pyrolysis and oxidation developed using multispecies time histories in shock-tubes, Combustion and Flame 161 (2014) 1135-1145.

[30] K.-Y. Lam, D.F. Davidson, R.K. Hanson, High-Temperature Measurements of the Reactions of $\mathrm{OH}$ with a Series of Ketones: Acetone, 2-Butanone, 3-Pentanone, and 2-Pentanone, Journal of Physical Chemistry A 116 (2012) 5549-5559.

[31] Z. Serinyel, N. Chaumeix, G. Black, J.M. Simmie, H.J. Curran, Experimental and Chemical Kinetic Modeling Study of 3-Pentanone Oxidation, Journal of Physical Chemistry A 114 (2010) 12176-12186.

[32] R.S. Tranter, R.W. Walker, Rate constants for $\mathrm{H}$ and $\mathrm{OH}$ attack on propanone, butanone and pentan-3-one at $753 \mathrm{~K}$, and the oxidation chemistry of the radicals formed, Phys. Chem. Chem. Phys. 3 (2001) 1262-1270.

[33] Z. Serinyel, G. Black, H.J. Curran, J.M. Simmie, A Shock Tube and Chemical Kinetic Modeling Study of Methy Ethyl Ketone Oxidation, Combustion Science and Technology 182 (2010) 574-587.

[34] D.F. Davidson, S.C. Ranganath, K.Y. Lam, M. Liaw, Z. Hong, R.K. Hanson, Ignition Delay Time Measurements of Normal Alkanes and Simple Oxygenates, Journal of Propulsion and Power 26 (2010) 280-287.

[35] K.-Y. Lam, W. Ren, S.H. Pyun, A. Farooq, D.F. Davidson, R.K. Hanson, Multi-species time-history measurements during high-temperature acetone and 2-butanone pyrolysis, Proceedings of the Combustion Institute 34 (2013) 607-615.

[36] K.-Y. Lam, W. Ren, Z. Hong, D.F. Davidson, R.K. Hanson, Shock tube measurements of 3pentanone pyrolysis and oxidation, Combustion and Flame 159 (2012) 3251-3263.

[37] Y. Li, L. Wei, Z. Tian, B. Yang, J. Wang, T. Zhang, F. Qi, A comprehensive experimental study of low-pressure premixed C 3-oxygenated hydrocarbon flames with tunable synchrotron photoionization, Combustion and Flame 152 (2008) 336-359.

[38] J.D. Koch, J. Gronki, R.K. Hanson, Measurements of near-UV absorption spectra of acetone and 3-pentanone at high temperatures, Journal of Quantitative Spectroscopy and Radiative Transfer 109 (2008) 2037-2044.

[39] G. Barari, S.M. Sarathy, S.S. Vasu, Improved combustion kinetic model and HCCI engine simulations of di-isopropyl ketone ignition, Fuel 164 (2016) 141-150.

[40] Y. Yang, J.E. Dec, Bio-Ketones: Autoignition Characteristics and Their Potential as Fuels for HCCI Engines, SAE Int. J. Fuels Lubr. 6(3) (2013) 713-728.

[41] J. Badra, A. Elwardany, F. Khaled, S.S. Vasu, A. Farooq, A shock tube and laser absorption study of ignition delay times and $\mathrm{OH}$ reaction rates of ketones: 2-Butanone and 3-Buten-2-one, Combust. Flame 161 (2014) 725-734.

[42] S.M. Sarathy, P. Oßwald, N. Hansen, K. Kohse-Höinghaus, Alcohol combustion chemistry, Prog. Energ. Combust. Sci. in press, available online (2014).

[43] S.M. Sarathy, S. Vranckx, K. Yasunaga, M. Mehl, P. Oßwald, W.K. Metcalfe, C.K. Westbrook, W.J. Pitz, K. Kohse-Höinghaus, R.X. Fernandes, H.J. Curran, A comprehensive chemical kinetic combustion model for the four butanol isomers, combustion and flame 159 (2012) 2028-2055.

[44] H.J. Curran, P. Gaffuri, W.J. Pitz, C.K. Westbrook, Combust. Flame 114 (1998) 149.

[45] S.S. Vasu, S.M. Sarathy, On the High-Temperature Combustion of n-Butanol: Shock Tube Data and an Improved Kinetic Model, Energy \& Fuels 27 (2013) 7072-7080. 
[46] S.H. Pyun, W. Ren, D.F. Davidson, R.K. Hanson, Methane and ethylene time-history measurements in n-butane and n-heptane pyrolysis behind reflected shock waves, Fuel 108 (2013) 557-564.

[47] B. Koroglu, O. Pryor, J. Lopez, L. Nash, S.S. Vasu, Shock tube ignition delay times and methane time-histories measurements during excess $\mathrm{CO} 2$ diluted oxy-methane combustion, Combustion and flame 164 (2016) 152-163.

[48] A.S. Pine, Self-, N2, O2, H2, Ar, and He broadening in the v3 band Q branch of CH4, The Journal of Chemical Physics 97 (1992) 773-785.

[49] S.H. Pyun, J. Cho, D.F. Davidson, R.K. Hanson, Interference-free mid-IR laser absorption detection of methane, Measurement Science and Technology 22 (2011) 025303.

[50] W.K. Metcalfe, S.M. Burke, S.S. Ahmed, H.J. Curran, A hierarchical and comparative kinetic modeling study of $\mathrm{C} 1-\mathrm{C} 2$ hydrocarbon and oxygenated fuels, International Journal of Chemical Kinetics 45 (2013) 638-675.

[51] E.R. Ritter, J.W. Bozzelli, THERM: Thermodynamic property estimation for gas phase radicals and molecules, International Journal of Chemical Kinetics 23 (1991) 767-778.

[52] Reaction Design, CHEMKIN-PRO 15112, San Diego, 2011.

[53] D.F. Davidson, R.K. Hanson, Int. J. Chem. Kinet. 36 (2004) 510.

[54] W. Tsang, Chemical Kinetic Data Base for Combustion Chemistry. Part 3: Propane, Journal of Physical and Chemical Reference Data 17 (1988) 887-951.

[55] W. Tsang, J. Phys. Chem. Ref. Data 20 (1991) 235.

[56] A. Singh, S.I. Olsen, P.S. Nigam, A viable technology to generate third-generation biofuel, Journal of Chemical Technology \& Biotechnology 86 (2011) 1349-1353.

[57] J. Mendes, C.-W. Zhou, H.J. Curran, Theoretical and Kinetic Study of the Reactions of Ketones with HÖ2 Radicals. Part I: Abstraction Reaction Channels, The Journal of Physical Chemistry A 117 (2013) 4515-4525.

[58] J. Badra, A. Elwardany, A. Farooq, Reaction rate constants of H-abstraction by $\mathrm{OH}$ from large ketones: measurements and site-specific rate rules, Phys. Chem. Chem. Phys. 161 (2014) 725-734.

[59] O. Welz, J. Zádor, J.D. Savee, L. Sheps, D.L. Osborn, C.A. Taatjes, Low-Temperature Combustion Chemistry of n-Butanol: Principal Oxidation Pathways of Hydroxybutyl Radicals, The Journal of Physical Chemistry A 117 (2013) 11983-12001.

[60] N. Cohen, Are reaction rate coefficients additive? Revised transition state theory calculations for $\mathrm{OH}+$ alkane reactions, International Journal of Chemical Kinetics 23 (1991) 397-417.

[61] C.-W. Zhou, J.M. Simmie, H.J. Curran, Ab initio and kinetic study of the reaction of ketones with $\mathrm{OH}$ for $T=500-2000 \mathrm{~K}$. Part I: hydrogen-abstraction from $\mathrm{H}_{3} \mathrm{CC}(\mathrm{O}) \mathrm{CH}_{3-\mathrm{x}}\left(\mathrm{CH}_{3}\right)_{\mathrm{x}}, \mathrm{x}=0 \rightarrow$ 3, Phys. Chem. Chem. Phys. 13 (2011) 11175-11192.

[62] D.M. Matheu, A.M. Dean, J.M. Grenda, W.H. Green, Mechanism Generation with Integrated Pressure Dependence: A New Model for Methane Pyrolysis, The Journal of Physical Chemistry A 107 (2003) 8552-8565.

[63] NIST kinetic databse: http://kinetics.nist.gov/kinetics/index.jsp, (2011).

[64] H.J. Curran, P. Gaffuri, W.J. Pitz, C.K. Westbrook, A comprehensive modeling study of iso-octane oxidation, combustion and flame 129 (2002) 253-280.

[65] R. Sumathi, H.H. Carstensen, W.H. Green, Reaction Rate Prediction via Group Additivity Part 1: H Abstraction from Alkanes by $\mathrm{H}$ and $\mathrm{CH}$, The Journal of Physical Chemistry A 105 (2001) 6910-6925. 
[66] P. Zhao, W. Yuan, H. Sun, Y. Li, A.P. Kelley, X. Zheng, C.K. Law, Laminar flame speeds, counterflow ignition, and kinetic modeling of the butene isomers, Proceedings of the Combustion Institute 35 (2015) 309-316.

[67]

M. Mehl, H. Curran, W. Pitz, C. Westbrook. Chemical kinetic modeling of component mixtures relevant to gasoline. In: editor^editors. European Combustion Meeting; 2009. p.

[68] P.R. Bevington, D.K. Robinson, Data reduction and error analysis, McGraw-Hill, New York, (2003).

[69] M. Nishida, G. Ben-Dor, O. Igra, T. Elperin, Chapter 4.1 - Shocktubes and Tunnels: Facilities, Instrumentation and Techniques, in: G. Ben-Dor, O. Igra, T. Elperin (Eds.), Handbook of Shock Waves, Three Volume Set, Academic Press2001. 


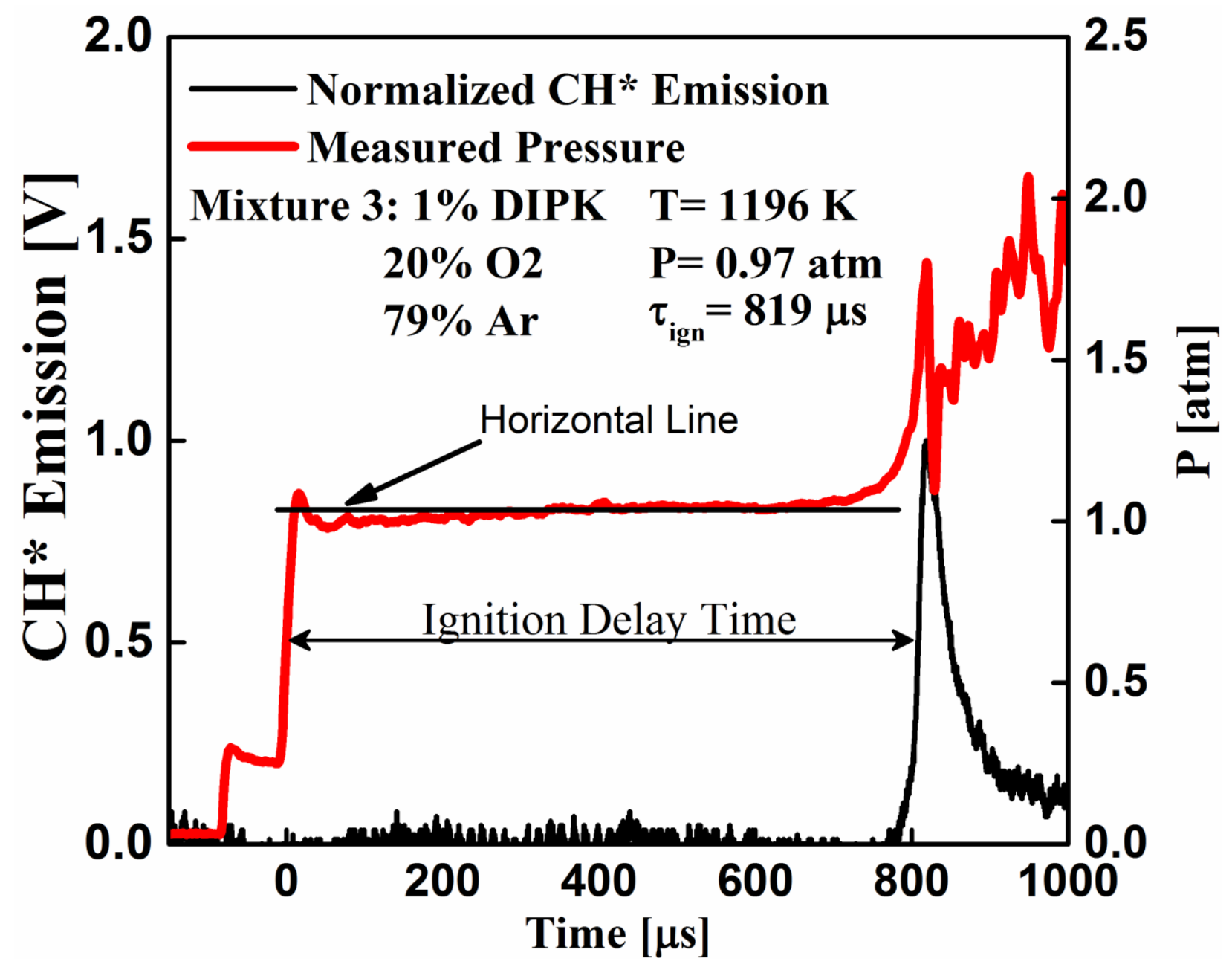




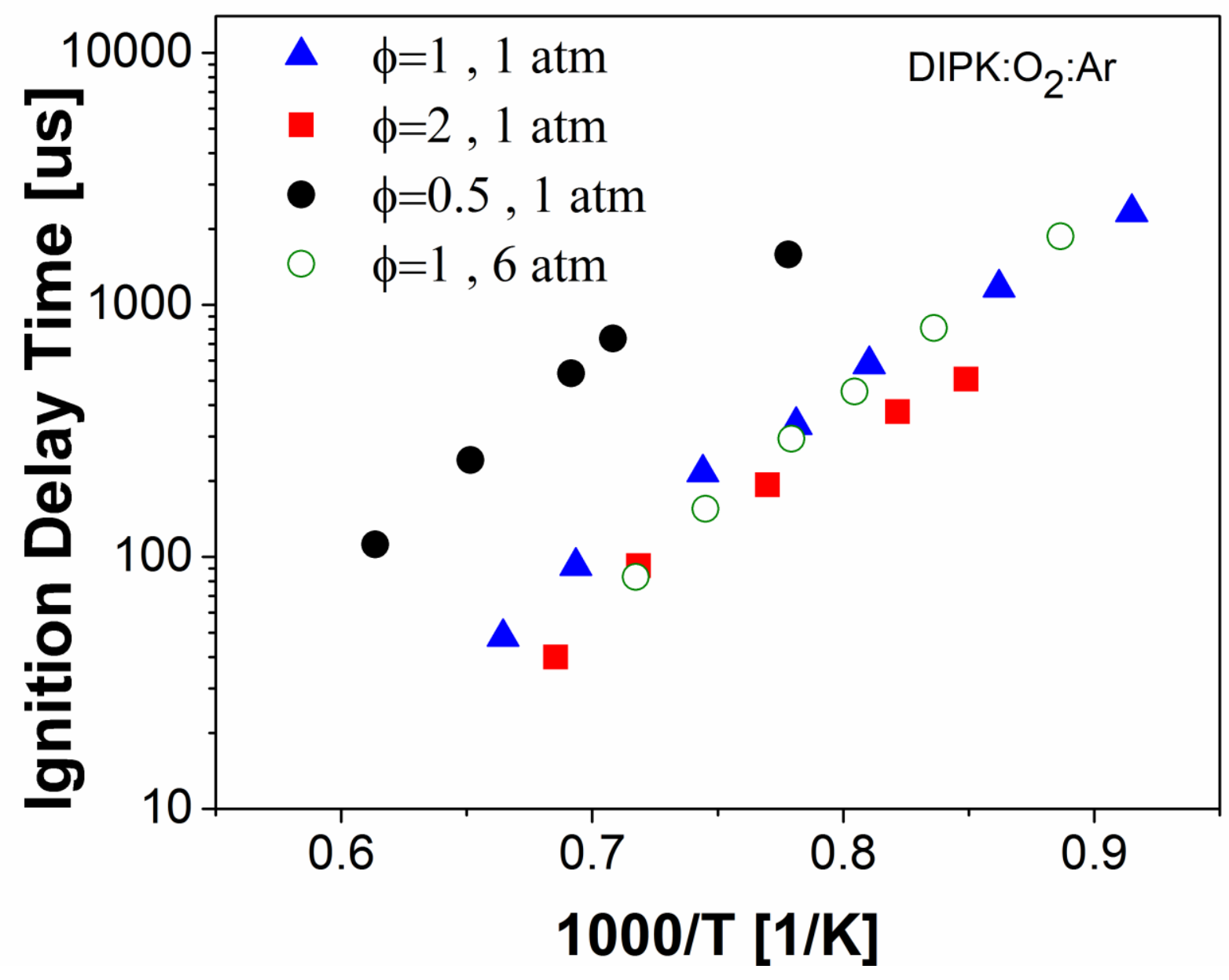




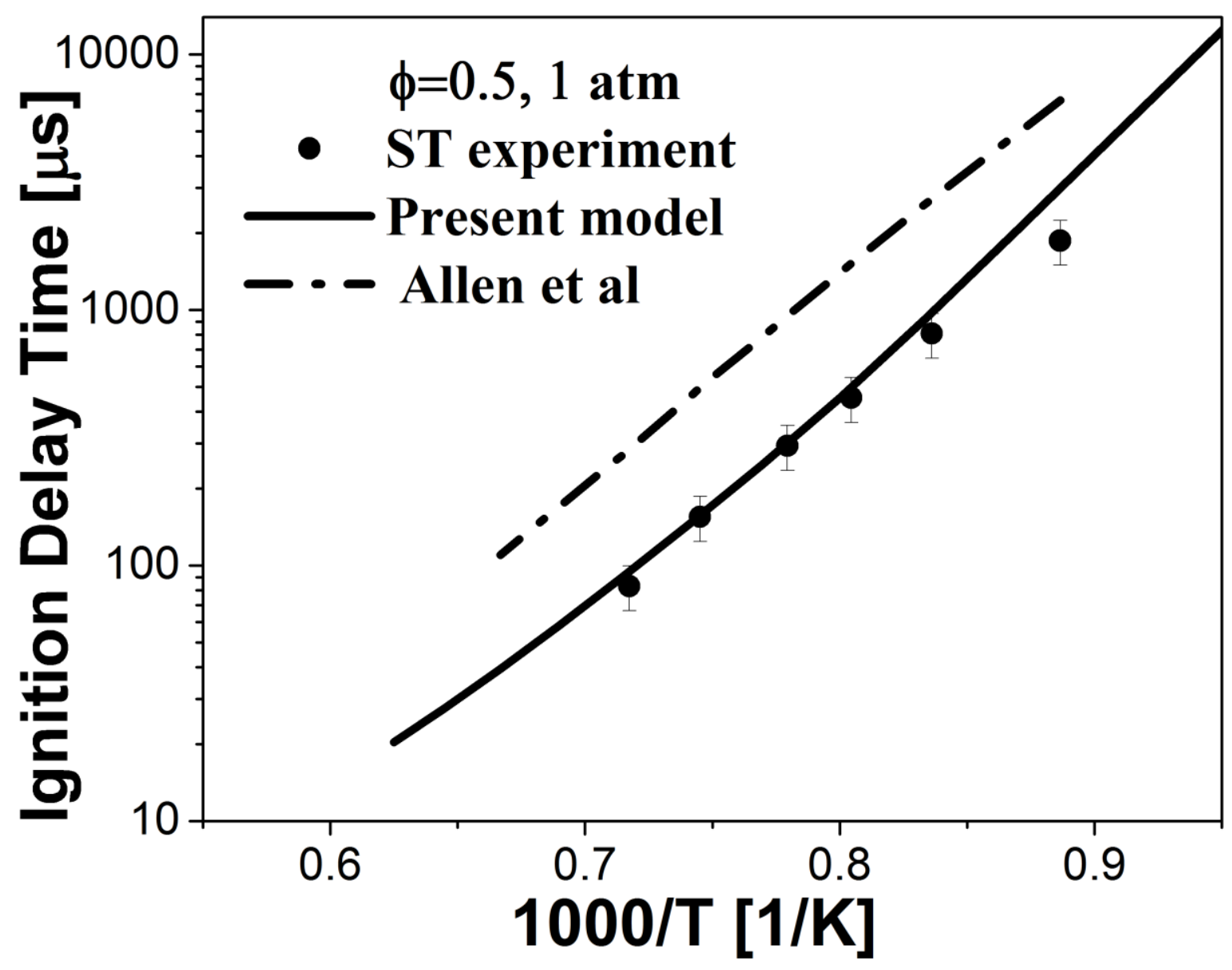




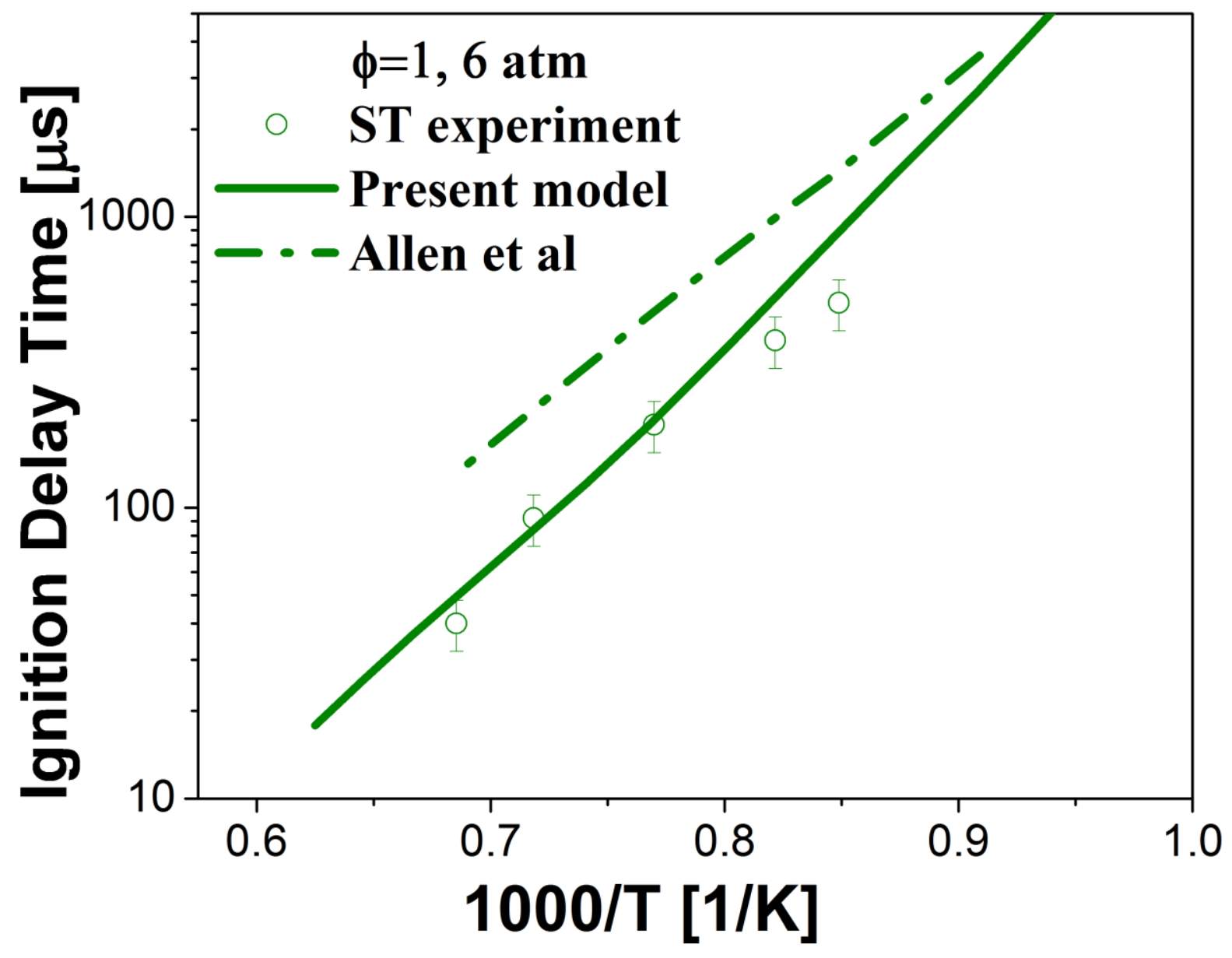




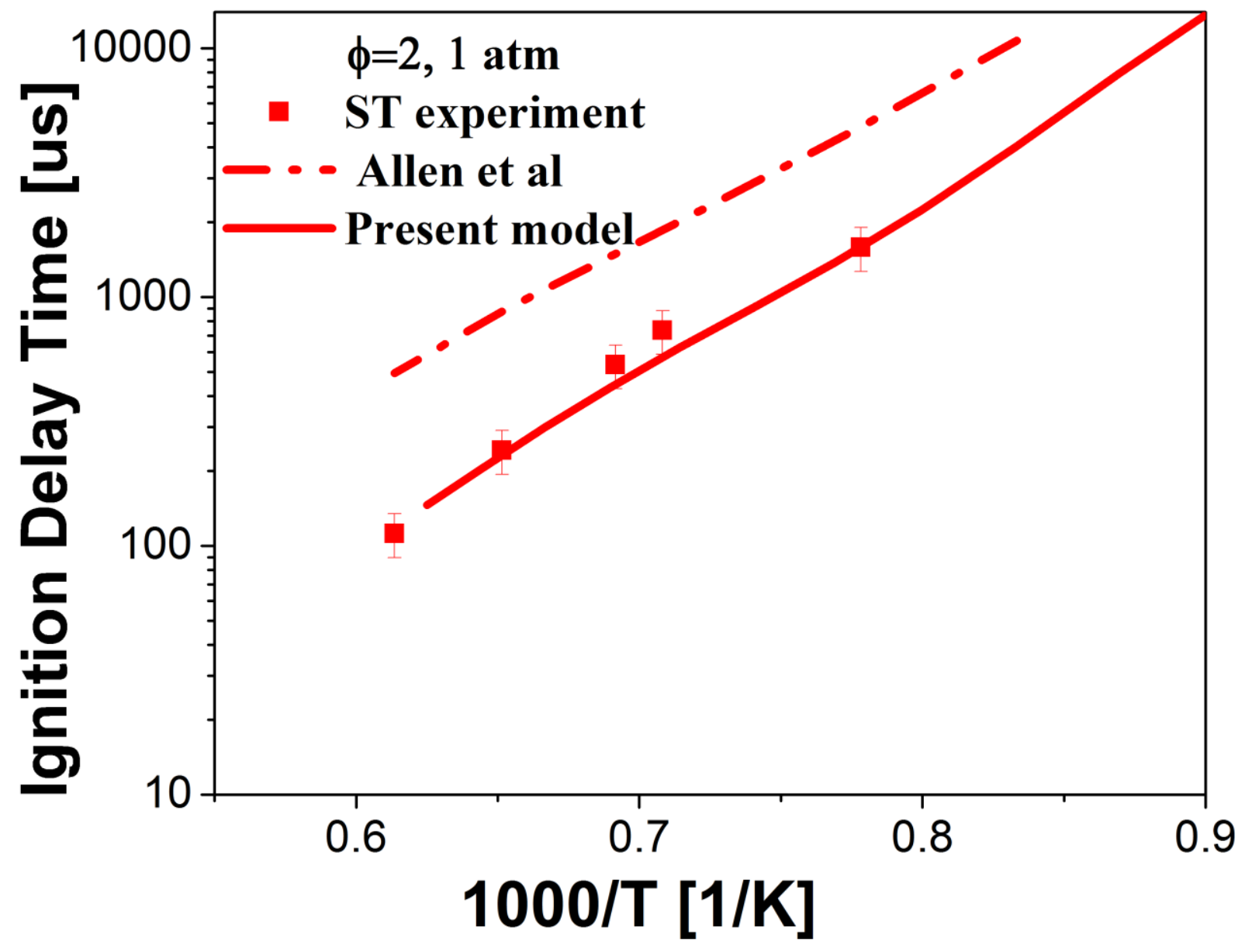




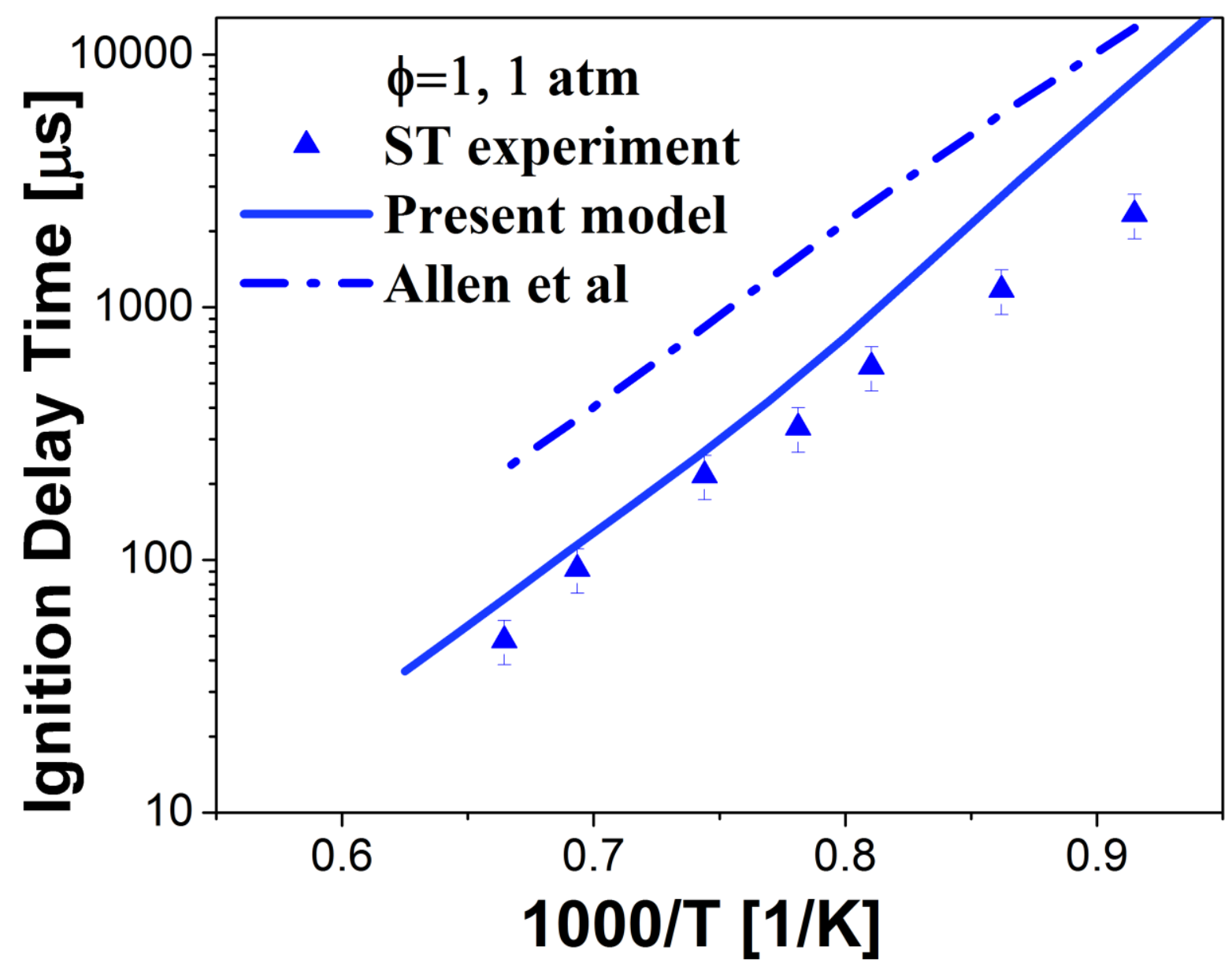




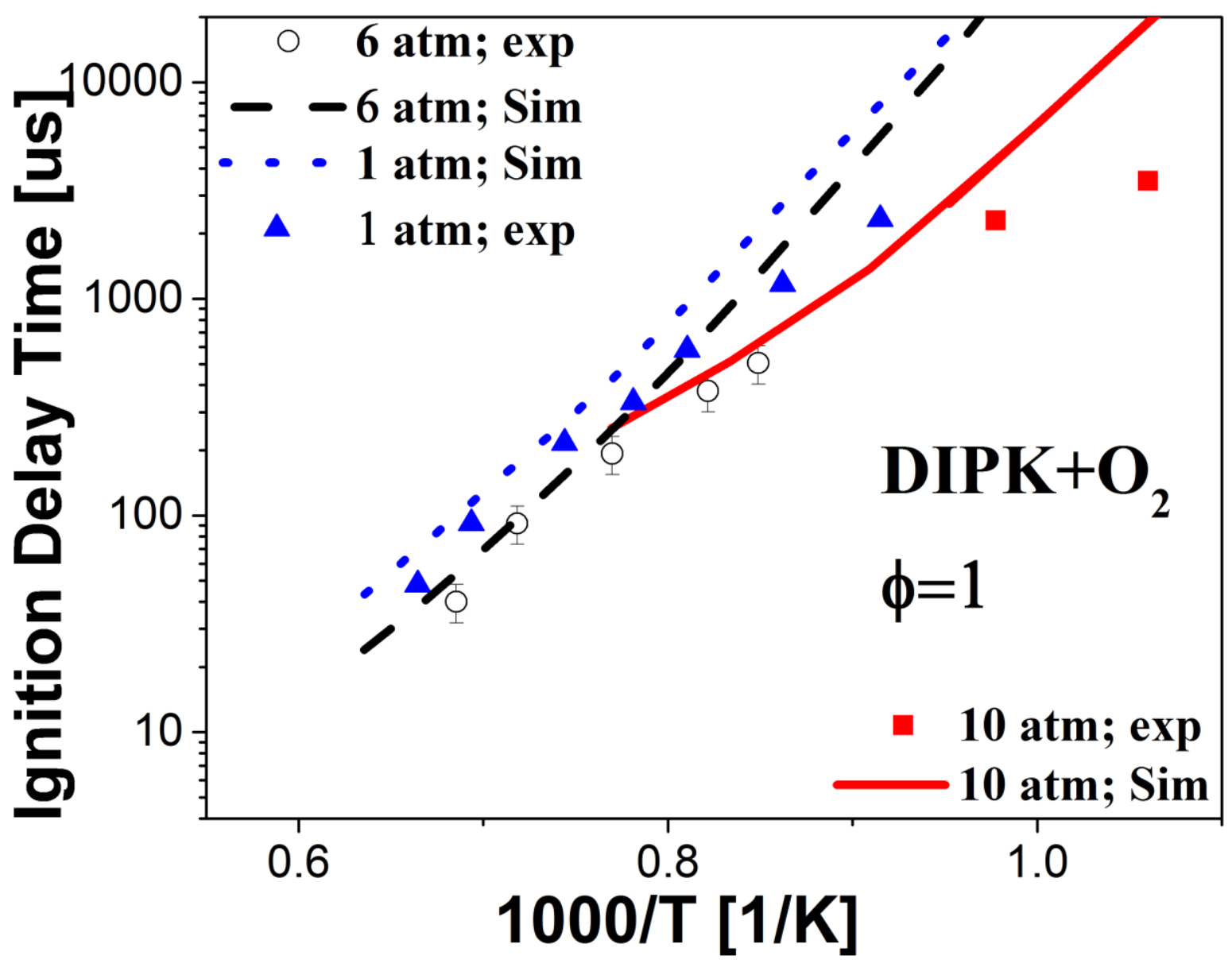




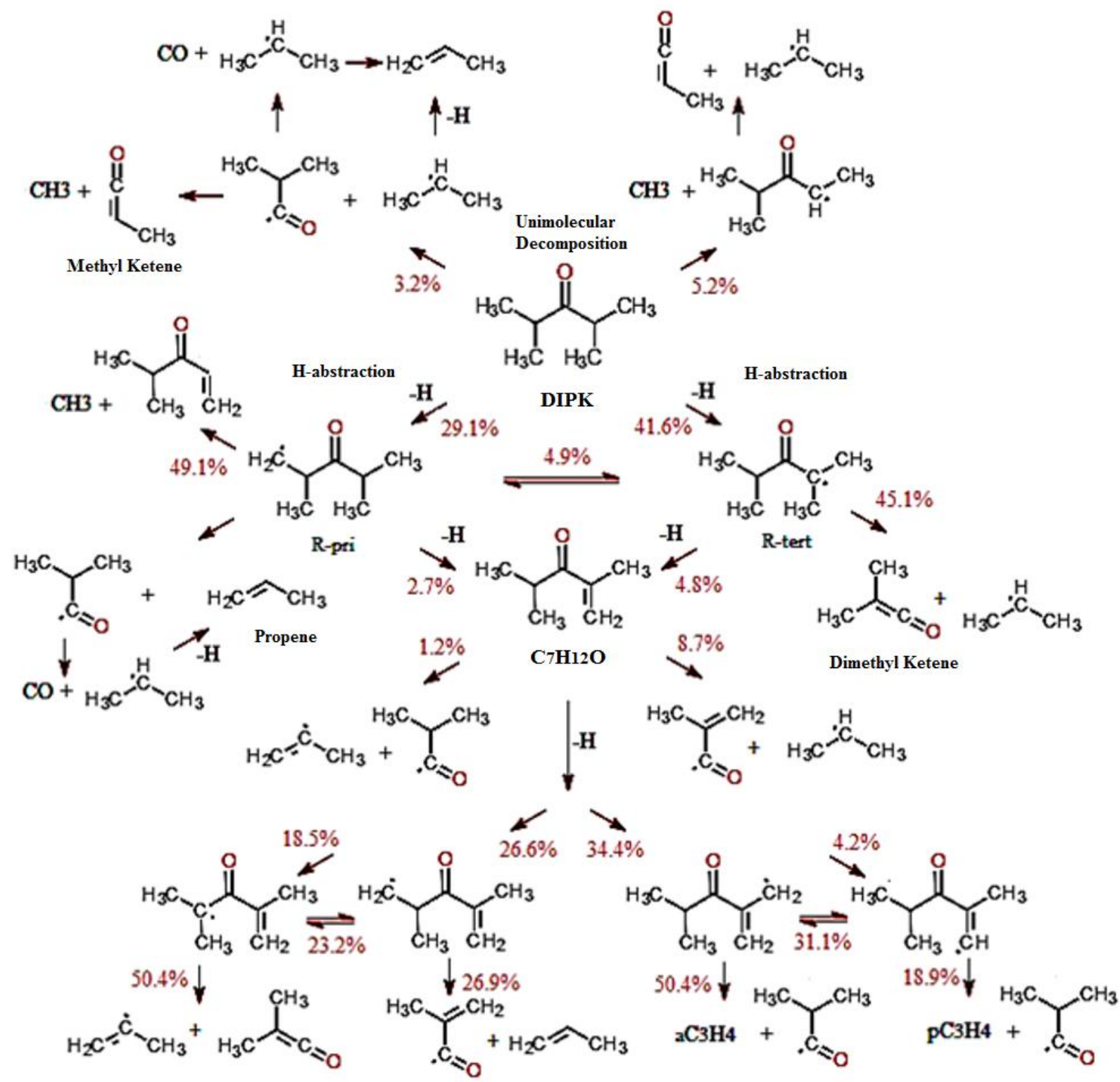




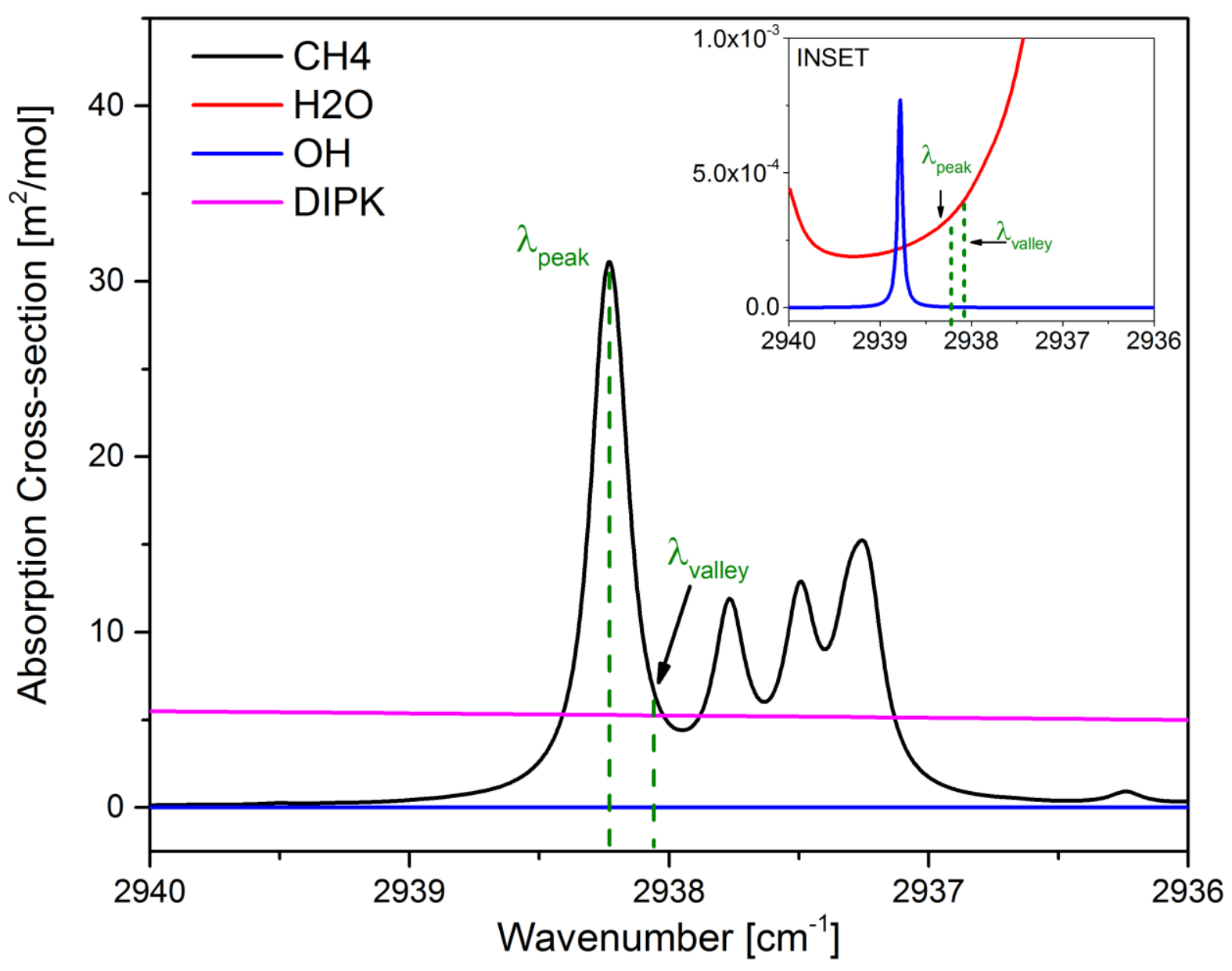




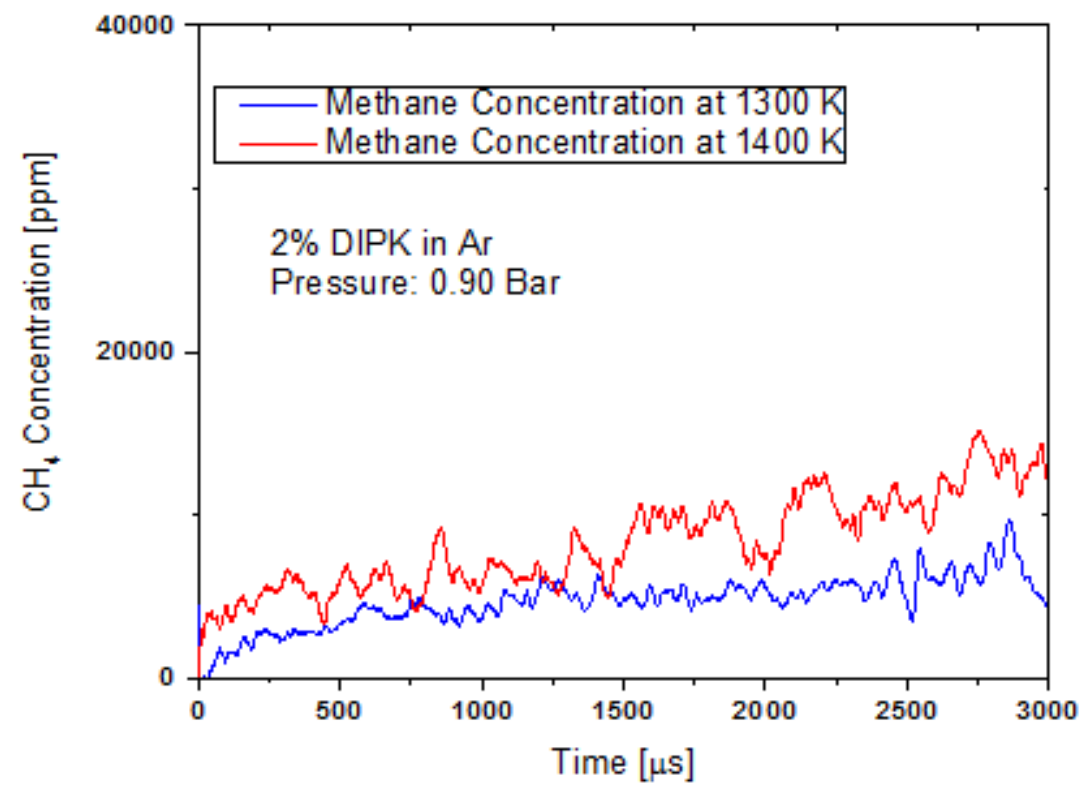




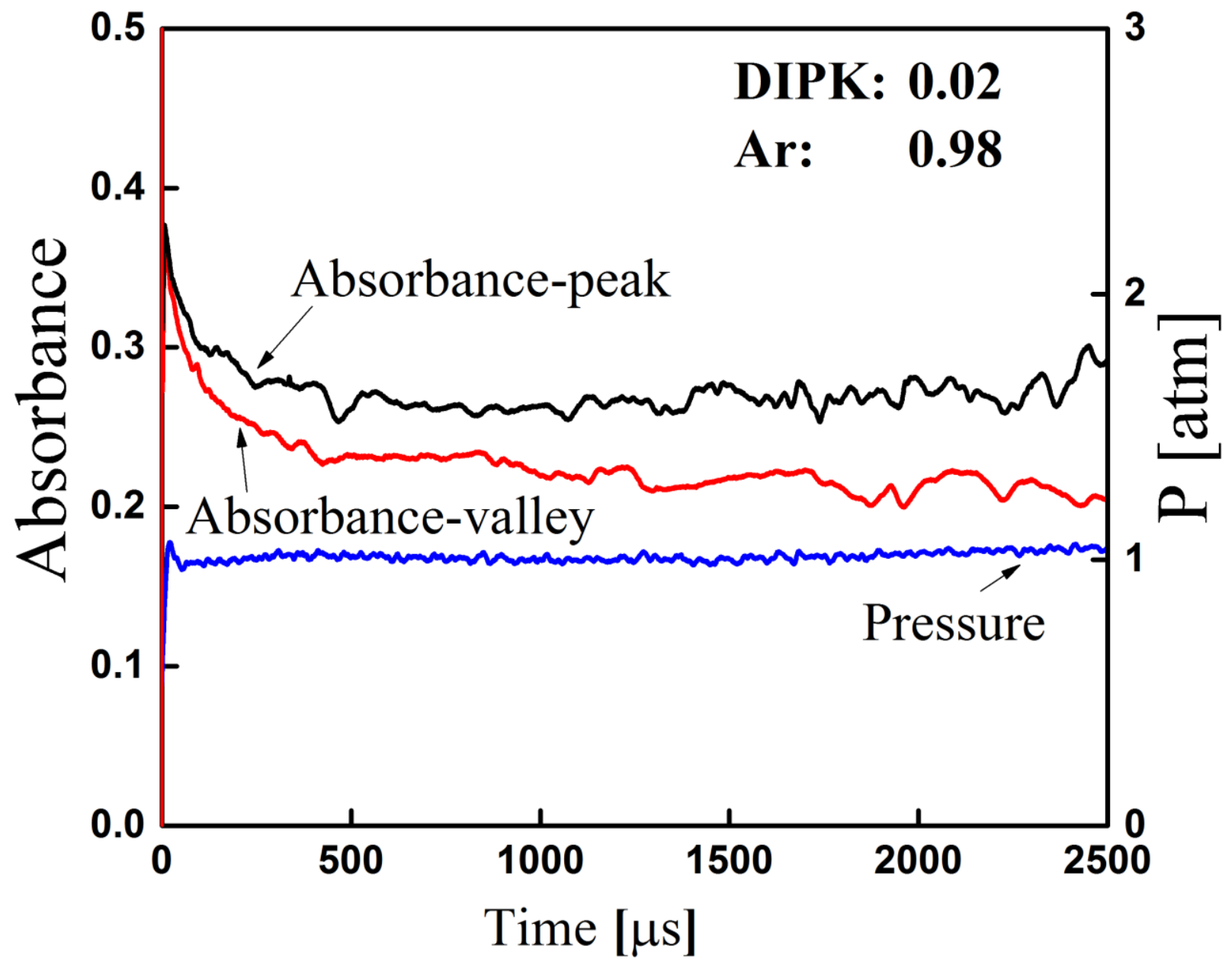




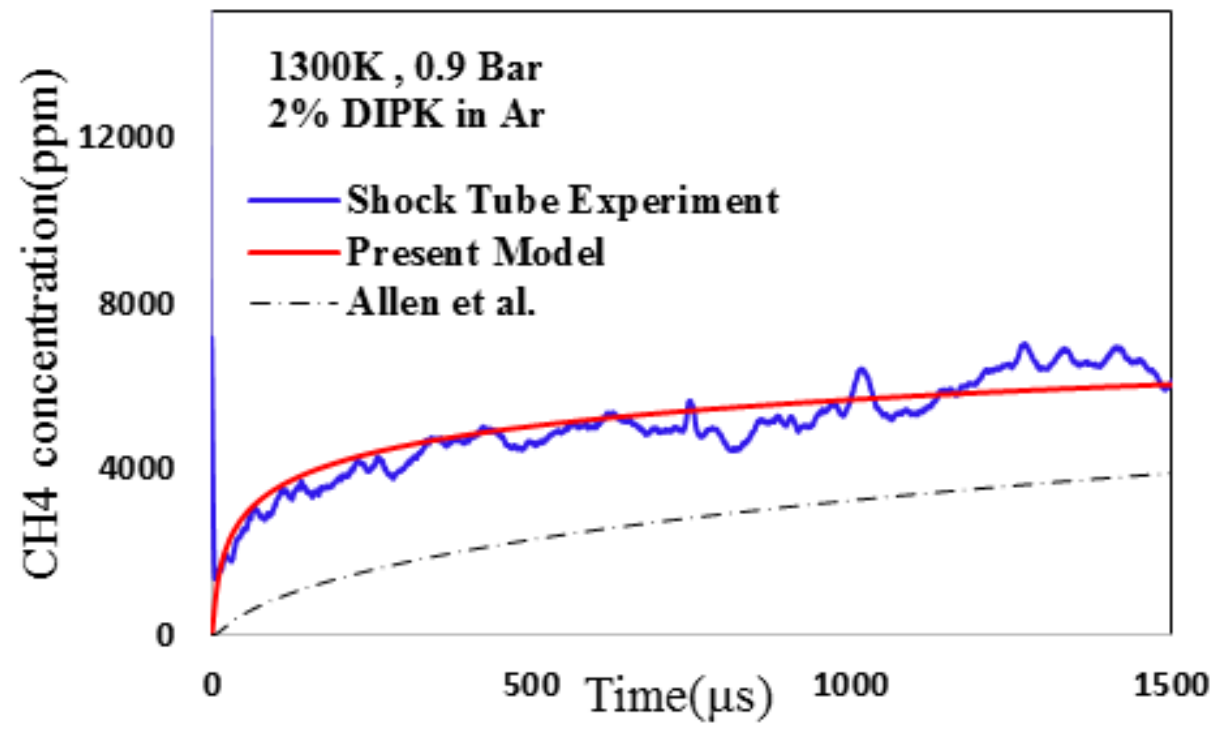




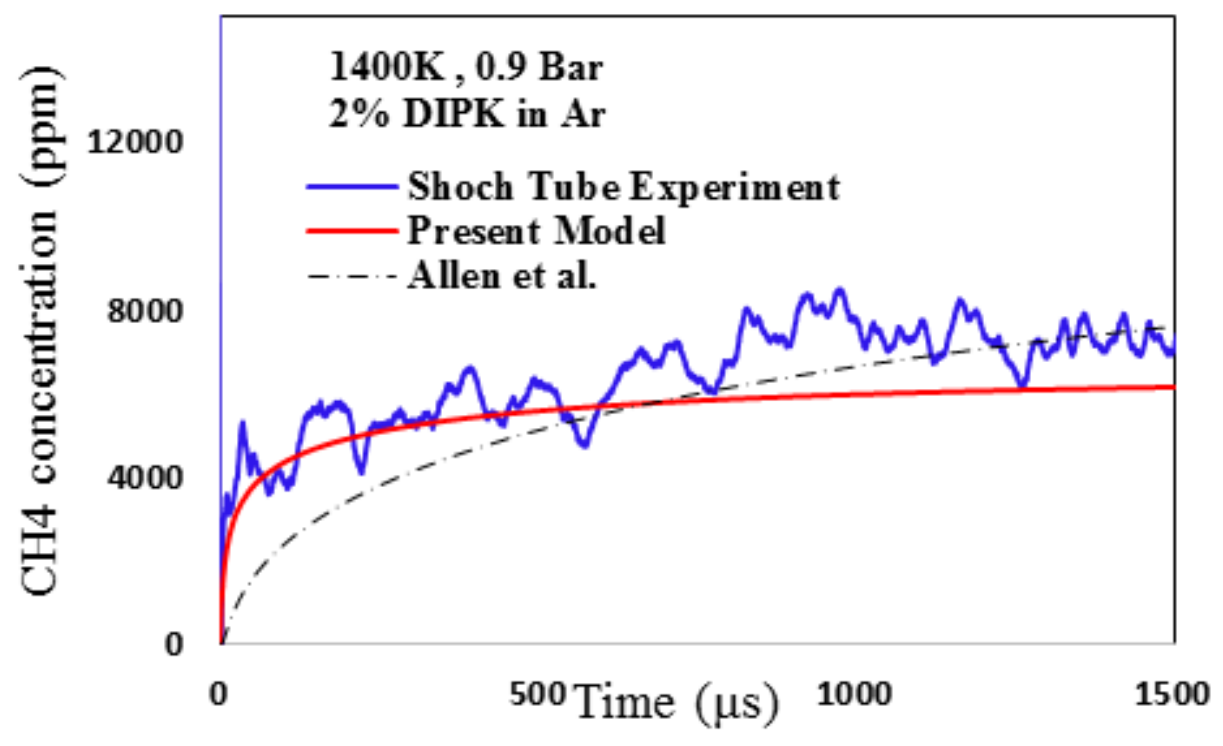


Normalized Sensitivity $\mathrm{OH}$

$\mathrm{H}+\mathrm{O} 2 \varsigma=>\mathrm{O}+\mathrm{OH}$

$\Rightarrow \mathrm{DIPK}+\mathrm{H} \Leftrightarrow=\approx \mathrm{R}$ _tert $+\mathrm{H}_{2}$

$5 \mathrm{CH} 3+\mathrm{C} 6 \mathrm{H} 110 \mathrm{~J} \leq=\mathrm{DIPK}$

$\mathrm{CH} 3+\mathrm{HO}_{2} \Leftrightarrow=\mathrm{CH} 3 \mathrm{O}+\mathrm{OH}$

$\mathrm{C} 3 \mathrm{H} 5-\mathrm{A}+\mathrm{HO} 2 \Leftrightarrow=\mathrm{C} 3 \mathrm{H} 5 \mathrm{O}+\mathrm{OH}$

$\mathrm{CH} 3+\mathrm{HO}_{2} \Leftrightarrow==\mathrm{CH}_{4}+\mathrm{O}_{2}$

$\mathrm{H}+\mathrm{C} 3 \mathrm{H} 6 \leq==1 \mathrm{C} 3 \mathrm{H} 7$

$2 \mathrm{HO} 2<=>\mathrm{H} 2 \mathrm{O} 2+\mathrm{O} 2$

$\mathrm{DIPK}+\mathrm{H} \Leftrightarrow=>\mathrm{R} \_$pri $+\mathrm{H} 2$

$2 \mathrm{CH} 3(+\mathrm{M}) \Leftrightarrow=>\mathrm{C} 2 \mathrm{H} 6(+\mathrm{M})$

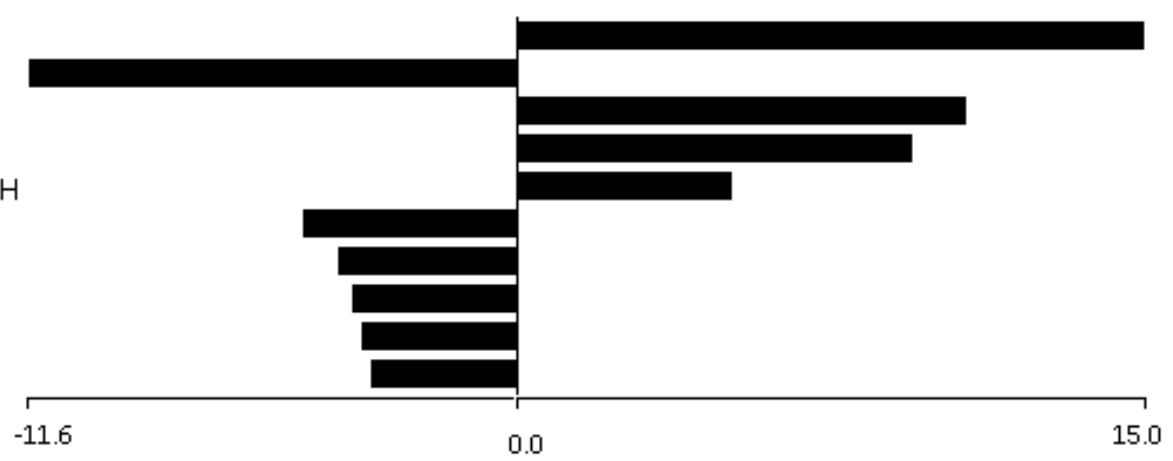




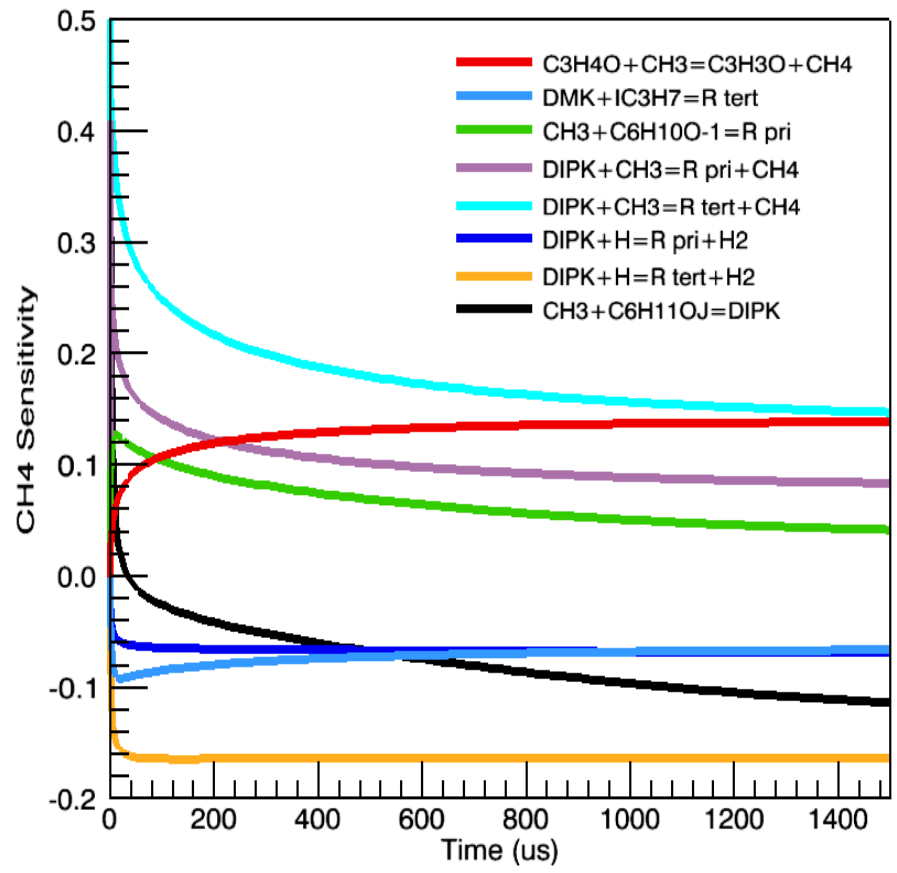




\begin{tabular}{cccccccc}
\hline Mixture & Pressure (atm) & $\varphi$ & $\begin{array}{l}\text { DIPK } \\
\%\end{array}$ & mole & $\mathrm{O}_{2}$ mole \% & Ar mole \% & Temperature range [K] \\
\hline 1 & 1 & 1 & 2 & 20 & 78 & $1093-1505$ \\
2 & 1 & 2 & 2 & 10 & 88 & $1285-1630$ \\
3 & 1 & 0.5 & 1 & 20 & 79 & $1128-1394$ \\
4 & 6 & 1 & 1 & 10 & 89 & $1178-1459$ \\
\hline
\end{tabular}




\begin{tabular}{lllll}
\hline Reaction & $\mathrm{A} \mathrm{cm}^{3} \mathrm{~mol}^{-1} \mathrm{~s}^{-1}$ & $\mathrm{n}$ & $\mathrm{Ea}\left(\mathrm{kcal} \mathrm{mol}^{-1}\right)$ & No. \\
\hline $\mathrm{DIPK}+\mathrm{H} \leftrightarrow \mathrm{R}_{\text {pri }}+\mathrm{H}_{2}$ & $2.660 \times 10^{6}$ & 2.450 & 6756 & (R 25) \\
$\mathrm{DIPK}+\mathrm{H} \leftrightarrow \mathrm{R}_{\text {tert }}+\mathrm{H}_{2}$ & $1.505 \times 10^{6}$ & 2.41 & 2556 & (R 26) \\
$\mathrm{DIPK}+\mathrm{OH} \leftrightarrow \mathrm{R}_{\text {pri }}+\mathrm{H}_{2} \mathrm{O}$ & $3.108 \times 10^{1}$ & 3.540 & -2909 & (R 27) \\
$\mathrm{DIPK}+\mathrm{OH} \leftrightarrow \mathrm{R}_{\text {tert }}+\mathrm{H}_{2} \mathrm{O}$ & $9.840 \times 10^{3}$ & 2.700 & -4036 & (R 28) \\
$\mathrm{DIPK}+\mathrm{HO}_{2} \leftrightarrow \mathrm{R}_{\text {prit }}+\mathrm{H}_{2} \mathrm{O}_{2}$ & $4.760 \times 10^{-3}$ & 4.560 & 15184 & (R 29) \\
$\mathrm{DIPK}+\mathrm{HO}_{2} \leftrightarrow \mathrm{R}_{\text {tert }}+\mathrm{H}_{2} \mathrm{O}_{2}$ & $1.696 \times 10^{0}$ & 3.53 & 11375 & (R 30) \\
$\mathrm{DIPK}+\mathrm{CH}_{3} \leftrightarrow \mathrm{R}_{\text {pri }}+\mathrm{CH}_{4}$ & $12.24 \times 10^{0}$ & 3.650 & 7150 & (R 31) \\
$\mathrm{DIPK}+\mathrm{CH}_{3} \leftrightarrow \mathrm{R}_{\text {tert }}+\mathrm{CH}_{4}$ & $4.68 \times 10^{3}$ & 2.71 & 3710 & (R 32) \\
DIPK $+\mathrm{C}_{2} \mathrm{H}_{5} \leftrightarrow \mathrm{R}_{\text {pri }}+\mathrm{C}_{2} \mathrm{H}_{6}$ & $2.000 \times 10^{11}$ & 0.0 & 13400 & (R 33) \\
DIPK $+\mathrm{C}_{2} \mathrm{H}_{5} \leftrightarrow \mathrm{R}_{\text {tert }}+\mathrm{C}_{2} \mathrm{H}_{6}$ & $2.646 \times 10^{10}$ & -0.19 & 10216 & (R 34) \\
DIPK $+\mathrm{O} \leftrightarrow \mathrm{R}_{\text {pri }}+\mathrm{OH}$ & $3.920 \times 10^{6}$ & 2.43 & 4750 & (R 35) \\
DIPK $+\mathrm{O} \leftrightarrow \mathrm{R}_{\text {tert }}+\mathrm{OH}$ & $2.214 \times 10^{6}$ & 2.30 & 550 & (R 36) \\
\hline
\end{tabular}




\begin{tabular}{llll}
\hline Mixture & Pressure (bar) & Temperature $(\mathrm{K})$ & Ignition delay time $(\mu \mathrm{s})$ \\
\hline & 0.912 & 1093 & 2330 \\
& 0.934 & 1160 & 1170 \\
1 & 0.948 & 1234 & 5841 \\
& 0.903 & 1280 & 333 \\
& 0.868 & 1344 & 216 \\
& 0.845 & 1442 & 92 \\
& 0.838 & 1505 & 48 \\
\hline \multirow{4}{*}{2} & 0.730 & 1285 & 1584 \\
& 0.836 & 1412 & 734 \\
& 0.842 & 1446 & 534 \\
& 0.791 & 1535 & 242 \\
& 0.756 & 1630 & 112 \\
\hline \multirow{4}{*}{3} & 1.012 & 1128 & 1867 \\
& 0.968 & 1196 & 808 \\
& 0.958 & 1243 & 453 \\
& 0.899 & 1342 & 155 \\
& 0.851 & 1394 & 83 \\
\hline \multirow{4}{*}{4} & 6.304 & 1178 & 506 \\
& 5.948 & 1217 & 373 \\
& 5.857 & 1299 & 193 \\
& 5.670 & 1392 & 92 \\
& 5.490 & 1459 & 40 \\
\hline
\end{tabular}

